\title{
Italian Industrial Districts: Theories, Profiles and Competitiveness
}

\author{
Daniele Schilirò ${ }^{1, *}$ \\ ${ }^{1}$ Department of Economics, University of Messina, Messina, Italy \\ *Correspondence: Department of Economics, University of Messina, Messina, Italy. E-mail: dschiliro@unime.it
}

Received: September 14, 2017 Accepted: October 14, $2017 \quad$ Online Published: October 25, 2017

doi:10.5430/mos.v4n4p1

URL: https://doi.org/10.5430/mos.v4n4p1

\begin{abstract}
The paper is a contribution to the debate about the theoretical aspects, the structure, and the competitiveness of Italian industrial districts. The work first examines the theoretical strand on industrial districts ranging from Marshall to Becattini, and focusing on the contemporary distrettualism of Giacomo Becattini, where the district is essentially a socio-economic construct and an important localized productive system. Furthermore, the paper offers an updated picture of the Italian industrial districts as they are represented in the 2011 Census by the National Statistics Institute. Finally, this study underlines the resilient competitive capacity of this typical form of industrial organization. Then, through empirical literature, it analyzes the Italian district companies, and their performance and success in foreign markets, especially with regard to "Made in Italy" products.
\end{abstract}

Keywords: industrial districts; Italian SMEs; exports; competitiveness

Jel Classification: D0, L23, M10

\section{Introduction}

Industrial districts composed of numerous small and medium firms characterize the Italian production system. Their presence and performance have been the subject of extensive and controversial discussion among industrial-organization scholars. Undoubtedly they have demonstrated a remarkable ability to overcome the difficulties of the economic crisis, and above all the changes associated with globalization and technological progress.

This paper is a contribution to the debate about the theoretical aspects, the structure, and the competitiveness of Italian industrial districts. The work first examines the theoretical strand on industrial districts, ranging from Marshall to Becattini, and focusing on the contemporary distrettualism of Giacomo Becattini, where the district is essentially a socio-economic construct and an important localized productive system. Furthermore, the paper offers an updated picture of the Italian industrial districts as they are represented in the 2011 Census by the National Statistics Institute. Finally, this study underlines the resilience and high degree of competitiveness of this typical form of industrial organization. Then, through empirical literature, it analyzes the Italian district companies, and their performance and success on foreign markets, especially with regard to "Made in Italy" products.

\section{The Theoretical Construct of Industrial District: From Marshall to Becattini}

The notion of "industrial district" was coined by Alfred Marshall in 1867, in some of his early writings where he refers to the textile industries of Lancashire and Sheffield. But the definition of industrial district appears in his work Industry and Trade (1919). According to Marshall, the districts are an original form of agglomeration of businesses, characterized by strong industrial specialization, where the local dimension of production within them has a key role in creating an environment more favorable to individual success.

Marshall noticed how the co-presence of firms in the same sector and in the same area would create an "industrial atmosphere" that could support and encourage the strengthening of local industry (Schilirò, 2012). Marshall found that an important determinant of the competitive success of industrial districts was the effective co-operation within and between firms, supported by a dense network of institutions, and markets regulated by agreed-upon rules, norms 
and standards. He theorized that these generate external economies of scale and scope, which enable the district and its constituent small firms to successfully compete with large, vertically integrated firms (Konzelmann \& Wilkinson, 2016).

However, in the mid-1920s with the emergence and growth of very large and highly successful firms, the conventional wisdom shifted to supposing that the historical tendency in capitalist development was toward large-firm dominance. The contribution of Marshall regarding industrial districts fell into oblivion.

In Italy, the notion of industrial district was revived by Giacomo Becattini during the 1960s and became operational in the 1970s. Becattini contributed the reorganization of Marshall's fundamental insights in an interpretive organic framework applied to the analysis of industrial districts in Italy (Schilirò, 2012). In 1979, Becattini published the article "Dal 'settore' industriale al 'distretto' industriale: alcune considerazioni sull'unità d'indagine dell'economia industriale"(Note 1) considered the theoretical reference point of contemporary distrettualism. From this article (Becattini, 1979) emerges the notion of Becattini's industrial district as a socio-economic system, where local development forces and territory become crucial.

With Becattini, the industrial district becomes a general model to broaden the understanding of alternative forms of industrial organization, primarily in the Italian economic system, but also in a more general way, in contemporary economic systems. His theoretical construct aims at describing and interpreting widespread industrialized phenomena in circumscribed territorial areas, which are characterized by the predominant presence of small and medium-sized enterprises, specialized in a single production chain.

In Becattini's interpretation, the industrial district is a new unit of analysis, representing an economic entity halfway between the single enterprise and the whole sector, which takes into account the production sites and the production communities with their specializations (Schilirò, 2008).

Giacomo Becattini $(1979,1989,2007)$ defines the industrial districts as socio-territorial entities formed by the active coexistence of a community of enterprises and people, united both by territorial relationships and by the socio-economic ties that such coexistence generates. Industrial districts are characterized by horizontal and vertical integration forms and also by production specialization(Note 2). Thus, if the Marshallian district was a simple aggregation of industrial and professional activities of the same species, located within the same geographic area, the Italian district, as Becattini describes it is identified by the presence of a community that is essentially a set of history, unwritten rules, and shared values, which directly affects the productivity and structure of the district itself. According to Becattini, the close relationship established between communities and businesses in the district is the key factor that drives innovation, knowledge and quality.

External economies play a key role in the success of industrial districts. These are advantages not internal to the individual company, but internal to the local system involving the same businesses, and therefore external to the single firm. In fact, industrial districts enjoy external economies due to the advantages of agglomeration, and rising returns due to the widening demand. So, the advantages of external economies are due to the industrial district as a whole. Examples of such advantages include the presence of a large and stable skilled workforce; access to production facilities; the ability to use in an easy way sophisticated machinery and common organizational methods; and in general, economies that are dependent on general industry development. The external economies of the district, however, are not limited to the economies of specialization (though they are relevant), but include learning economies and economics of creativity and innovation (Bellandi, 2003). Learning economies are linked to the characteristics of the local labor market and derive from the on-site presence of highly skilled professionals. The economics of creativity and innovation translates into widespread innovative capacity, thanks to the proximity of the actors, the sharing of specific skills and experience, and advanced technical-scientific training.

Another important and peculiar aspect of industrial districts is the existence of a mix of complex relationships of cooperation and competition between district firms. Among the goods and services created in the districts, there are complementary relationships in some cases (e.g. placing companies at different levels in the production chain), and substitutability in others. Thus, we witness the combination of competition and collaboration ('co-petition') between companies - for example, with competition in the reference market and simultaneous practices of mutual cooperation. All this implies that in the district, the relationships between the different subjects are competitive but 'non-destructive'. Indeed, it is the correct balance between collaboration and competition that creates the stimulus for continuous renewal, and allows the development of new opportunities for district companies to stimulate innovation. (Note 3) 
In this complex representation of the district model, demand plays a crucial role. Indeed, the affirmation of a more differentiated, customized demand expresses itself through choices that are not only rational, but also emotional, and where choosing a product type often must also reveal social prestige. Demand mainly linked to various income levels and cultural sensibilities of those who express it becomes the expression of a society where emotions, feelings, and aesthetics are the reference parameters of consumption choices (Schilirò, 2012). Consequently, demand becomes more fragmented and variable, while the standardized product loses ground.

Becattini's conceptualization of the industrial district as a model of production served as a turning-point for applied research on localized production systems. Several scholars in other countries carried out studies on industrial districts and their centrality for local and regional development (e.g., Piore \& Sabel, 1983; Storper \& Harrison, 1991; Ellison \& Glaeser, 1997; Duranton \& Overman, 2002).

Certainly, one of the most influential has been Michael Porter with his notion of the industrial or business cluster. In his view, the cluster is a localized system of production of which the Italian industrial district is a special case. Porter $(1990,1998)$ describes the cluster as being composed of industries connected through vertical (buyer/supplier) and horizontal (common customers, technology, distribution channels) relationships. According to Porter, clusters are geographic concentrations of inter-connected companies, specialized suppliers, service providers, firms in related industries, and associated institutions (for example, universities, standards agencies, and trade associations) in particular fields, which compete but also cooperate. Although enormously successful as a conceptual and policy tool, Porter's cluster has been strongly criticized on several bases. In particular, Sforzi $(2015$, p. 20) argues that its relationship with the industrial district concept has been distorted by identifying the unit of analysis as "a mere geographic concentration of industries" and focusing on the economic determinants of performance. Instead, following Becattini's line of thought, Dei Ottati (2009) and Sforzi (2015) underline that the industrial district is a socio-economic construct. Therefore, the interconnections between the production system and the community of people insisting on the same territory represent the basic source of the proper functioning of processes that characterize the district model and its adaptability to change.

However, in Italy after the theoretical contribution of Becattini, the adoption of a methodology for the identification of industrial districts by official statistics (i.e., the National Statistics Office) has marked an important moment for the quantitative study of the phenomenon, thanks above all to the work of Sforzi \& Lorenzini (2002), who proposed a territorial classification in operational terms, consistent with the theoretical district model. Over time, there have been several other contributions that have increased the knowledge and expertise around the original methodological framework (Sforzi, 2007).

\section{A Picture of Italian Industrial Districts}

The presence of a large number of businesses of a reduced average size, with increased production localization, characterizes the Italian production system.

Small and medium enterprises (SMEs) are one of the driving forces of the national economy. The main feature of Italian SMEs lies in their organizational form, which has found its most complete expression in industrial districts.

Istat, the National Statistics Institute, through the $9^{\text {th }}$ General Industrial and Services Census of 2011 (Istat, 2015), identified 141 industrial districts, 40 units less than the number of industrial districts surveyed in the previous Census of 2001.

Since 2008, the global crisis has influenced the decade 2001-2011, hitting the production systems of European countries, and Italy in particular. Above all, the effects of the crisis have been felt in job losses. The decline in employment was especially significant in manufacturing, with 919,000 (19\%) fewer people. The census data for 2001 and 2011 highlight the combined effect of the crisis and the historical process of tertiarization of the Italian economy. Both phenomena have contributed to influencing the territorial configuration of the Italian district model, which, alongside the reduction in the number of districts, shows a greater concentration in the territories of the country where the districts were historically present (Istat, 2015).

In more detail, Istat data confirms that industrial districts account for about a quarter of the country's production system in terms of workers ( $24.5 \%$ of the total) and local production units ( $24.4 \%$ of the total). The Italian manufacturing sector is particularly strongly characterized by the district model. The manufacturing-industry districts account for more than a third of all Italian manufacturing, in line with what was observed 10 years ago. Industrial districts absorb $65.8 \%$ of manufacturing industry workers, while about $22 \%$ of the Italian population is within the industrial districts. 
With respect to the geography of the Italian industrial districts, Table 1 shows that the largest number of districts (45) is in the Northeast, which is traditionally the territorial reference area of the Italian district model. The Northwest the area's oldest industrialization in the country, once dominated by territorial formations of large enterprise - has 37 districts, while the center of Italy has 38 districts. In the South, there are 17 districts, concentrated in Puglia (7), Campania (6), and Abruzzo (4). In the Islands, the districts exist only in Sardinia (4), where all local manufacturing systems have the characteristics of the districts.

Industrial districts are distributed unevenly in 15 regions of the national territory. The macro-region formed by Lombardy, Veneto and Emilia-Romagna contains 70 industrial districts, accounting for $49.6 \%$ of the total. The historic district regions of Central Italy (Tuscany and Marche) recorded the presence of 34 districts, equal to $24.1 \%$. Thus, these five regions represent $73.8 \%$ of Italian districts. Lastly, the South and the Islands together hold only $14.9 \%$ of the total industrial districts.

In the 2011 Census, the district model is completely absent in six autonomous regions or provinces: Valle d'Aosta, Bolzano, Molise, Basilicata, Calabria, and Sicily(Note 4).

Table 1. Geographical Distribution of Italian Industrial Districts (Census, 2011)

\begin{tabular}{lc}
\hline Areas & Number of districts \\
\hline North- East & 45 \\
North- West & 37 \\
Center of Italy & 38 \\
South & 17 \\
Islands & 4 \\
Total (Italy) & 141 \\
\hline
\end{tabular}

Source: Istat (2015)

Table 2. Italian Industrial Districts: Main Indicators. Years 2011 and 2001. Absolute Values and Percent Variations

\begin{tabular}{lrrcc}
\hline & \multicolumn{2}{c}{ Absolute Values } & Variations 2011/2001 & \% Variations \\
\cline { 2 - 5 } & 2011 & 2001 & & $2011 / 2001$ \\
\hline Districts & 141 & 181 & -40 & -22.1 \\
Local Units & $1,152,429$ & $1,104,663$ & 47,766 & 4.3 \\
Employees & $4,887,527$ & $4,802,081$ & 85,446 & 1.8 \\
Manufacturing & & & & \\
Local Units & 164,737 & 210,081 & $-45,344$ & -21.6 \\
Manufacturing & & & & -21.0 \\
Local Units Employees & $1,504,490$ & $1,904,066$ & $-399,576$ & -6.8 \\
Number of Municipalities & 2,121 & 2,275 & -154 & 8.5 \\
Population & $13,326,320$ & $12,276,845$ & $1,049,475$ & \\
\hline
\end{tabular}

Source: Istat (2015).

Table 2 shows the main indicators for Italian industrial districts and a comparison between the values found in 2011, and those of the previous 2001 census. The table indicates that the districts suffered a numerical reduction in the decade 2001-2011. In fact, the number of districts decreased in absolute terms from 181 in 2001 to 141 in 2011. However, in 2011, the districts show a positive employment balance. Local district- unit employees, in fact, went from $4,802,081$ to $4,887,527$ units, with a variation of $+1.8 \%$. This variation is due to a sharp rise in the number of local units themselves, ranging from 1,104,663 to $1,152,429(+4.3 \%)$. Consequently, compared to 2001, although their number decreased, districts retain the same share of local units (24\%), workers employed (25\%) and resident 
population (22\%). Of course, the decrease in the number of districts is part of the overall restructuring in the Italian economy over the decade considered.

Another important change concerns the field of specialization. The composition of the productive specializations in the districts changed sharply. The presence of employees registered in 2011 in mechanical engineering was 38\%, showing a significant increase compared to 2001, when this share was only $36.2 \%$. This increase occurred at the expense of textiles and clothing (decreasing from $26.6 \%$ in 2001 to $20.3 \%$ ), the household goods sector (from $16.1 \%$ to $10.7 \%$ ), and the leather and footwear sector (from 12.3\% to 9.7\%) (Istat, 2015, pp. 25-26). The trend is similar for local units.

Therefore, the 2011-2001 variation analysis highlights the economic/occupational strengthening of the mechanical and, above all, the metallurgical industry. Conversely, household goods and leather and footwear mark the most negative dynamics, followed by textiles, clothing, jewelry and musical instruments.

On the other hand, Table 3 shows the average dimension, with respect to several parameters of Italian industrial districts in the years 2011 and 2001.

Table 3. Average Dimension of Italian Industrial District - Years: 2011, 2001 (absolute values)

\begin{tabular}{lll}
\hline Average Dimension & 2011 & 2001 \\
\hline $\begin{array}{l}\text { Number of } \\
\text { Municipalities }\end{array}$ & 15 & 13 \\
Resident & & \\
$\begin{array}{l}\text { Population } \\
\text { Local Units }\end{array}$ & 94,513 & 67,828 \\
Employees & 8,173 & 6,103 \\
for 100 inhabitants & 37 & 39 \\
$\begin{array}{l}\text { Manufacturing } \\
\text { Local Units }\end{array}$ & 1,168 & \\
$\begin{array}{l}\text { Manifacturing } \\
\text { Employees }\end{array}$ & 10,670 & 1,161 \\
\hline
\end{tabular}

Source: Istat (2015)

The data shown in this section help to provide a representation of the structure of the Italian industrial districts, which constitute the backbone of manufacturing production. The data also reveal the irregular territorial distribution of district firms, highlighting the weakness of the manufacturing system in southern Italy, and the high concentration of districts in some regions of the North. Furthermore, despite the crisis, districts have continued to create jobs, while local units have increased.

So, despite criticisms and distrust toward the district system, the 9th Census data on districts remains encouraging.

\section{Success of Italian District Companies in Foreign Markets and "Made in Italy"}

The success of Italian district companies in foreign markets is controversial among industrial-organization scholars. This section aims to show, through empirical literature (although not exhaustive), the resilience, flexibility, and high degree of competitiveness of Italian district companies, which determine their success in international markets.

Industrial districts are very important for Italian exports. In fact, at present, the exports of industrial districts are driving Italian exports, representing more than $60 \%$ of the total products exported by Italian industry. The territorial areas with the highest share of exports are those characterized by a strong presence of districts whose firms are driven into foreign markets, because of the specialization in production and the search for wider markets.

In turn, "Made in Italy" products represent the spearhead of Italian exports. "Made in Italy" can be identified as a set of goods strongly associated with the image of the country in the world. In fact, "Made in Italy" is synonymous 
with quality, and defined as the set of cultural values and human, technical, scientific, creative and production assets that characterize the Italian production system, involving the manufacturing districts, but also the numerous micro-systems of production geographically distributed in various areas of the country (Schilirò, 2012).

The 2011 Census (Istat, 2015) highlights that main district specializations are those typical of "Made in Italy" - that is, mechanical, textile and clothing, home goods and furniture, leather and footwear, food, goldsmith and jewelry, and musical instruments. The districts of "Made in Italy" total 130, representing $92.2 \%$ of the industrial districts of the country.

Undoubtedly the global crisis of 2008 , and the competitive pressures exerted by emerging countries on typical district production, have created problems for the Italian districts system, in many cases reducing the localization and performance advantages of district companies (Di Giacinto, Gomellini, \& Micucci, 2012; Bentivogli, Quintiliani, \& Sabbatini, 2013). However, Cipolletta \& De Nardis (2012) and Coltorti (2012), propose a different and less negative assessment of the competitiveness of Italian manufacturing districts and their companies, while acknowledging some critical points. These authors emphasize the importance of skills networks in districts as a strategic asset. In turn, tis wealth of expertise fosters significant innovative activity. Of course, not all district companies have been able to react to difficulties, to innovate or possess the skills appropriate to the evolution of the markets. Therefore, many businesses were forced out of the market, with negative effects on employment.

Today, Italian industrial districts are quite different from those studied by Becattini in the 1960s and 1970s. The districts have undergone a transformation in search of more suitable competitive behaviors, with a growing weight of leading companies of greater size, more inclined to innovate and internationalize, and capable of leading the production chain. Thus, a large group of companies, some of which are medium-sized firms, composes the new districts. In addition, Italian industrial districts have international networks in terms of production and distribution (Schilirò, 2011). Furthermore, they tend to privilege a vertical integration to a horizontal integration. However, some fundamental features persist, such as external economies, productive specializations, close relationships with local territories, creativity, and the so-called "Italian taste". In the districts, the share of firms that export is more than a third (38.4\%), well beyond the number of non-district firms (29.4\%). In addition, Italian district have the highest percentage of companies with export activities and internationally registered brands $(32.7 \%)$, compared to non-district firms (25.8\%) (Intesa San Paolo, 2016).

A key factor in the success of Italian district companies in foreign markets is innovation, especially product innovation. In fact, the territorial and productive proximity of district companies favors processes of creating and transmitting knowledge and innovation. Thus, thanks to their productive organization peculiarities, Italian districts express their own potential in situations of greater complexity, uncertainty, and risk, being able to adapt quickly and creatively to sudden changes in the external environment. Nevertheless, the process of innovation within industrial districts follows various paths, depending on the specific sector in which it develops, and on the multifaceted composition of the districts. Furthermore, innovation is strongly influenced by the internationalization process that becomes a stimulus and a constraint at the same time (Schilirò, 2015). Economic literature on innovation has generally confirmed the relationship between sectors and factors such as knowledge, technologies, production processes, demand, and heterogeneous population of firms and institutions (Schilirò, 2012).

An important aspect of small and medium-sized manufacturing firms of Italian districts is that they need workers with higher skill levels. They require specific qualifications that come from a unique synthesis of various kinds of knowledge. These peculiar qualifications reflect highly sophisticated and often exclusive specializations that make the Italian companies highly competitive and attractive in global markets. Unfortunately, the university system in Italy often appears unable to produce human capital adequate to the needs of companies that must compete globally. In addition, intangible capital (i.e., managerial capital, organizational capital, intellectual property, design, brand, and specific skills) plays an essential role and becomes of fundamental importance for accessing global value chains. In fact, Italian district companies export not only finished goods, but also intermediate goods that enter the final exports of companies of other countries, in the complex scenario of global trade. The economic literature that confirms the relevance of intangible capital is extensive, as the studies on the effects on growth (i.e., Corrado, Hulten \& Sichel, 2009; Corrado, Haskel, Jona-Lasinio, \& Iommi, 2012), or the examination of the relationship between intangible assets and global value chains (Sturgeon, 2013). Other studies concern the analysis of the impact of intangible assets on the success of SMEs (Steenkamp \& Kashyap, 2010; Ng \& Kee, 2012). But there are also empirical studies on Italian manufacturing SMEs showing a positive relationship between intangibles and firm performance (Cucculelli \& Bettinelli, 2015; Cantele \& Campedelli, 2016). 
A relevant hallmark of Italian industrial districts and their "Made in Italy" products is their capability of showing resilient and lasting competitiveness. According to the survey developed in Rapporto 2015 by Osservatorio Nazionale Distretti Italiani (2016), Italian district companies, albeit with a wide variety of behaviors and outcomes, have shown a high degree of competitiveness in foreign markets. This strength is the result of complex strategies focused not only on excellent production, increasingly stressing quality more than quantity, but also on an open and complex dialogue with the reference markets. Furthermore, district companies have changed their competitive positioning from cost leadership to differentiation leadership. Therefore, the key to growth in the global scenario is to strive for increasing differentiation, and not just in the strength of the brand name generically defined as "Made in Italy". Thus, product innovation, loyalty strategies, and direct control of after-sales services abroad are all fundamental levers for the growth of businesses in foreign markets, more significant than the price (Osservatorio Nazionale Distretti Italiani, 2016). Of course, leading or larger companies have taken full advantage of this strategy, more so than the small district firms. One criticism of Italian districts concerns investments, which are very important to boosting exports, but overall considered still inadequate (Osservatorio Nazionale Distretti Italiani, 2016). Another criticism is that the small size of the business is accompanied by family-ownership structure and management practices, often reluctant to assume the risks of innovation and unable to tackle global markets. This is especially true for micro-businesses that have less than 10 employees. Moreover, small companies have difficulty financing themselves due to limitations on bank credit imposed by Basel 3. Indeed, the stock market (Milan Stock Exchange) offers various possibilities for small and medium-sized firms to list in AIM, STAR or even MTA. But the conditions for access to these markets (especially STAR and MTA) are complex and stringent. On the other hand, the venture capital market, which is the specialized financing method to foster the rapid growth of innovative start-ups, is still poorly developed in Italy.

However, generally, the industrial district system confirms its ability to adapt to changing market dynamics. So, Italian industrial districts constitute "economies in motion" (Schilirò, 2012, p. 5), able to emerge and adapt to changing external conditions, and always looking for new markets. These "economies in motion" can shape in new forms the networks on which they stand. Knowledge, expertise, production, and marketing networks have progressively stretched, shifting to new functions as networks for innovation, research, and training.

Marco Fortis, in his book The Pillars of the Italian Economy (2016), shows that the ability to withstand challenge and gain significant success in foreign markets remains a key feature for many district firms. In fact, Italy is still a major country in manufacturing, not at all in decline when it comes to international trade. The country is the strongest European manufacturer after Germany and Italy is one of the five G-20 countries, along with China, Germany, Japan and South Korea, in the non-food manufacturing sector. There are 932 Italian products out of a total of 5,117, according to the index devised by Fortis and Corradini to measure the competitive excellence in international trade (Fortis, 2016, p. 9). The index represents positions of excellence in the worldwide trade balance, especially for high value-added "niche" products.

Fortis (2016) identifies the factors of success of the Italian industrial districts in foreign markets. Over time, the Italian districts have become a formidable territorial production machine, gaining advantage from agglomerated economies. Although in the last decade the manufacturing sector has undergone a downsizing, nevertheless, after a process of deep transformation and restructuring, it is still vital. Of course, the winning companies that have successfully overcome the years of crisis are those that have been able to innovate and internationalize and to focus on quality and higher value-added content. Wine, bio-pharmaceuticals, machines and mechanical equipment, and wrapping and packaging, just to name a few, have become the new winning Italian products on global markets. Consequently, "Made in Italy" still represents the excellence of Italian production in the world. According to Fortis (2016, p. 10), the strength of "Made in Italy" derives from the extensive diversification of its specializations(Note 5), driven mainly by the "4F" macro-sectors (Fashion and cosmetics; Food and wine; Furniture and ceramic tiles; Fabricated metal products, machinery and transport equipment), but also by other important sectors such as metallurgy, paper, and chemicals-pharmaceuticals. Creativity, innovation, quality, design, and a strong tradition of "industrial craftsmanship", (the ability to build customized products for clients), even in the high-tech sectors such as mechanical engineering or transportation vehicles, are the winning factors of "Made in Italy" and Italian SMEs.

Another fundamental aspect concerning the structure of production of Italian districts today is that the Italian economic system has experienced a deep transformation of its industrial specializations, changing the composition of its production among sectors. This deep transformation has been determined by the need to counter Asian competition, especially after the entrance of China into the WTO in 2001. 
Product specializations today are very different from what they were 20 years ago. The mechanical engineering sector in particular has become the driving force of "Made in Italy" manufacturing specializations. Thus, the weight of the traditional sectors of fashion and furniture in the manufacturing surplus declined to about $30 \%$, and compared to the past, it is currently composed mainly of higher value- added and luxury items. At the same time, there is a significant increase in the production of metal products and mechanical engineering (which includes equipment and industrial machinery, and home and electrical appliances), and means of transport other than automobiles (such as luxury yachts, cruise ships, and helicopters), but also of high-tech products including chemical, pharmaceutical and cosmetics products. This transformation of specializations has consequently changed the export composition and the content of the trade surplus of Italian firms. In terms of machines and mechanical equipment (excluding metal products), the mechanical engineering sector, in terms of machines and mechanical equipment (excluding metal products), has an export quota that, at present, is almost double of the traditional "Made in Italy" sector (e.g., fashion). Furthermore, as an example, pharmaceuticals were the fastest-growing category of products, up $42.7 \%$ in value for the seven-year period 2009-2016 (Fortis, 2016).

Another report - Economia e Finanza dei Distretti Industriali (Intesa-San Paolo, 2016) - shows through empirical evidence that the performance of district companies in terms of turnover is better than that of non-district businesses. Many districts have become almost exclusive locations for certain productions. Also, several industrial districts are seeing the return of production previously performed outside the national boundaries (reshoring), which also attracted the interest of foreign multinationals. Italian industrial districts showing better performance are characterized by some common phenomena: propensity to invest in innovation; efficient governance; presence of several leading companies coordinating numerous chains; high autonomy of subcontracting companies; and synergies with universities and research center. Thus, the resilience of business districts able to recover the ground lost during the crisis and return to 2008 sales levels, while firms outside the districts still chase pre-crisis profits, is remarkable.

Finally, in 2016, exports of Made in Italy exceed 400 billion euros. Italian exports in the first quarter of 2017 and the good prospect for the entire 2017-2018 biennium (Intesa-San Paolo, 2017), show the momentum of Italian companies. In fact, exports grow more rapidly than the world average, with export levels and trade balance reaching new records (Istat, 2017). All this confirms the relatively high level of competitiveness of Italian firms, and of industrial districts. It also demonstrates the high flexibility of Italian district companies, and their success in capturing the growth opportunities in the markets, leveraging quality and diversification of production and good inclusion in international supply chains. However, this positive scenario contrasts with the growth rate of the Italian economy and its modest growth in productivity. Consequently, the competitiveness of the country system is lower than that of its industrial enterprises.

\section{Conclusions}

This paper is a contribution to the debate about the theoretical aspects, the structure, and the competitiveness of Italian industrial districts. The work highlights the theoretical strand on industrial districts, ranging from Marshall to Becattini, and focusing on the contemporary distrettualism of Giacomo Becattini. Moreover, it provides an overview of the Italian industrial districts as the National Statistics Institute represents them in the 2011 Census, offering an updated picture of these important localized productive systems. In addition, the paper proposes an analysis of the Italian district companies in foreign markets, especially for "Made in Italy" productions. The empirical investigations by the Osservatorio Nazionale Distretti (2016), Fortis (2016) and Intesa-SanPaolo $(2016,2017)$ confirm the ability of Italian manufacturing districts, and the high degree of competitiveness of their companies. The main elements that emerge from the present analysis are the following.

First, since the crisis, Italian districts have undergone a deep transformation of their industrial specializations by adapting to changing external conditions and looking for new markets by gaining advantage from agglomerated economies.

Second, success in foreign markets seems to depend more on a set of factors, given the complexity of the markets, but innovation is undoubtedly a key factor.

Third, district companies have changed their competitive positioning from cost leadership to differentiation leadership. Furthermore, internationalization is the first strategy of successful district companies. Exports have proved to be the pillar of this internationalization process in the past few years. Thus, Italian 
manufacturing companies and their "Made in Italy" products are performing well in international trade; district companies are doing even better, compared to non-district firms.

Finally, there is heterogeneity in the performance of the district companies, which depends on sector/specialization, acting as a leader in the value chain, and synergies with universities and research centers. This last factor is important, since it could make districts the new centers of expertise and knowledge, with the effect of further strengthening their competitive capacity.

\section{References}

Becattini, G. (1979). Dal 'settore' industriale al 'distretto' industriale: alcune considerazioni sull'unità d'indagine dell'economia industriale. Rivista di economia e politica industriale, 1, 7-21.

Becattini, G. (1989). Riflessioni sul distretto industriale marshalliano come concetto socio-economico. Stato $e$ Mercato, 25, 111-128.

Becattini, G. (2000). Il Distretto Industriale. Un nuovo modo di interpretare il cambiamento economico. Torino: Rosenberg \& Sellier.

Becattini, G. (2007). Il Calabrone Italia. Ricerche e Ragionamenti sulla Peculiarità Economica Italiana. Bologna: Il Mulino.

Becattini, G. (ed.) (1987). Il mercato e forze locali: il distretto industriale. Bologna: Il Mulino.

Bellandi, M. (2003). Mercati, industrie e luoghi di piccola e grande impresa. Bologna: Il Mulino.

Bentivogli, C., Quintiliani, F., \& Sabbatini, D. (2013). Il contratto di rete: limiti e opportunità. L'Industria, 2, 347-348.

Cantele, S., \& Campedelli, B. (2016). Internationalization and performance of SMEs: exploring the moderating effects of intangible assets and capital intensity. International Journal of Business and Globalization, 17(2), 205-223. https://doi.org/10.1504/IJBG.2016.078407

Cipolletta, I., \& De Nardis, N. (2012). L'Italia negli anni duemila: poca crescita, molta ristrutturazione. Economia italiana, 1, 63-98.

Coltorti, F. (2012). L'industria italiana tra declino e trasformazione: un quadro di riferimento. QA. Rivista dell'Associazione Rossi-Doria, 2, 7-50.

Corrado, C., Haskel, J., Jona-Lasinio, C., \& Iommi, M. (2012). Intangible capital and growth in advanced economies: measurement methods and comparative results. IZA discussion paper No.6733.

Corrado, C., Hulten, C., \& Sichel, D. (2009). Intangible capital and U.S. economic growth. Review of Income and Wealth, 3, 661-685. https://doi.org/10.1111/j.1475-4991.2009.00343.x

Cucculelli, M., \& Bettinelli, C. (2015). Business models, intangibles and firm performance: evidence on corporate entrepreneurship from Italian manufacturing SMEs. Small Business Economics, 45(2), 329-350. https://doi.org/10.1007/s11187-015-9631-7

Dei Ottati, G. (2006). L'effetto distretto: alcuni aspetti concettuali. Economia Marche, 25(2), 69-82.

Di Giacinto, V., Gomellini, M., \& Micucci, M. (2012). Mapping Local Productivity Advantages in Italy: Industrial districts, cities or both? Bank of Italy Working Paper No.850.

Duranton, G., \& Overman, H. (2002). Testing for Localisation Using Micro-Geographic Data. CEPR Discussion Paper, $n .3379$.

Ellison G., \& Glaeser E.L. (1997). Geographic Concentration in U.S. Manufacturing Industries: A Dartboard Approach. Journal of Political Economy, 105(5), 889-927. https://doi.org/10.1086/262098

Fortis, M. (ed.) (2016). The Pillars of the Italian Economy, Cham: Springer. https://doi.org/10.1007/978-3-319-40186-7

Fortis, M., \& Quadrio Curzio, A. (eds.) (2006). Industria e distretti. Un paradigma di perdurante competitività, Bologna, Il Mulino.

Intesa-San Paolo. (2016). Economia e Finanza dei Distretti Industriali, Rapporto annuale, n. 9. Milano: Direzione Studi e Ricerche. 
Intesa-San Paolo, (2017). Monitor dei Distretti e dei Poli Tecnologici. Milano: Direzione Studi e Ricerche.

Istat (2015). I distretti industriali 2011. $9^{\circ}$ Censimento dell'industria e dei servizi e Censimento delle istituzioni non profit. Roma.

Istat (2017). Rapporto sulla competitività dei settori produttivi. Roma: Istat.

Jona-Lasinio, C., Manzocchi, S., \& Meliciani, V. (2016). Intangible assets and participation to global value chains: an analysis on a sample of European countries, LLEE Working Paper, 126, 1-29.

Konzelmann, S., \& Wilkinson, F. (2016). Co-operation in production, the organization of industry and productive systems: a critical survey of the 'district' form of industrial organization and development, Centre for Business Research. University of Cambridge, Working Paper No. 481.

Lipparini, A. (2002). La gestione strategica del capitale intellettuale e del capitale sociale. Bologna: Il Mulino.

Marshall, A. (1890). Principles of Economics. London: Macmillan.

Marshall, A. (1919). Industry and Trade. London: MacMillan.

Ng, H.S., \& Kee, D.M. (2012). Intangible factors affecting the success of small and medium enterprises (SMEs), International Journal of Management \& Organizational Studies, 1(2), 10-15.

Osservatorio Nazionale Distretti Italiani (2016). Rapporto 2015. Roma: Unioncamere.

Piore, M., \& Sabel, C. (1983). Italian small business development: Lessons for U.S. industrial policy. In J. Zysman \& L. Tyson (eds.), American Industry in International Competition: Government Policies and Corporate Strategies. Ithaca: Cornell University Press.

Porter, M. (1998). On Competition. Boston: Harvard Business School Press.

Porter, M. (1990). The Competitive Advantage of Nations. London: Macmillan. https://doi.org/10.1007/978-3-319-40186-7

Schilirò, D. (2008). I distretti industriali in Italia quale Modello di Sviluppo Locale: Aspetti evolutivi, potenzialità e criticità. Milano: Vita e Pensiero.

Schilirò, D. (2010). I distretti produttivi in Sicilia. Analisi e proposte per la competitività. Economia e Società Regionale, 111(3), 92-113.

Schilirò, D. (2011). Innovation and Performance of Italian Multinational Enterprises of the "Fourth Capitalism". Journal of Advanced Research in Management, 2(1), 89-103.

Schilirò, D. (2012). Italian industrial districts. A model of success or a weak productive system? AAPP |Atti della Accademia Peloritana dei Pericolanti. Classe di Scienze Fisiche, Matematiche e Naturali, 90(S1), C2-1 C2-12.

Schilirò, D. (2015). Innovation in Small and Medium Enterprises in the United Arab Emirates. International Journal of Social Science Studies, 3(5), 148-160. https://doi.org/10.11114/ijsss.v3i5.1014

Sforzi, F. (2007). The industrial districts' contribution to change in the Italian economy. Economia Italiana, 1, 80-95.

Sforzi, F. (2015). Rethinking the Industrial District: 35 Year Later. Journal of Regional Research, 32, 11-29.

Sforzi, F., \& Lorenzini, F. (2002). I distretti industriali. In Istituto per la Promozione Industriale (IPI)- Ministero delle Attività Produttive, L'esperienza dei distretti industriali (pp.20-33). Rome: Ministero delle Attività Produttive.

Steenkamp, N., \& Kashyap, V. (2010). Importance and contribution of intangible assets: SME managers' perceptions. Journal of intellectual capital, 11(3), 368-380. https://doi.org/10.1108/14691931011064590

Storper, M., \& Harrison, B. (1991). Flexibility, hierarchy and regional development: the changing structures of production systems and their forms of governance in the 1990s. Research Policy, 20(5), 407-422. https://doi.org/10.1016/0048-7333(91)90066-Y

Sturgeon, T. (2013). Global Value Chains and Economic Globalization. Report to Eurostat. Brussels: Eurostat. 


\section{Notes}

Note 1. The English translation of the article, entitled "Sectors and/or Districts: Some Remarks on the Conceptual Foundations of Industrial Economics" was published in E. Goodman, J. Bamford, and P. Saynor, (1989), Small firms and industrial districts in Italy, London: Routledge, pp. 136-152.

Note 2. There is vertical integration when each company belonging to the district is specialized in a single stage (or a few stages) of the production cycle. One of the main reasons for vertical integration in districts is the reduction in transaction costs. There is horizontal integration instead if the companies of the district carry out similar activities in the same production process.

Note 3. Marco Fortis, "I distretti produttivi e la loro rilevanza nell'economia italiana: alcuni profili di analisi”, in Fortis and Quadrio Curzio (2006).

Note 4. Since 2007, Sicily has experienced the development of productive districts that encompass both industrial districts and districts from non-industrial sectors such as agriculture, wine, and fishing. The productive districts recognized by the Sicilian region were 23, nine of which were industrial districts, but the experience was not very successful (Schilirò, 2010). However, in its 2011 Census, Istat has not acknowledged any industrial district in Sicily.

Note 5. This Fortis thesis is perfectly coherent with that of the Osservatorio Nazionale Distretti Italiani (2016). 


\title{
Determinants of Internet Banking Adoption by Banks in Pakistan
}

\author{
Muhammad Ali Raza ${ }^{1, *}$, Muhammad Naveed ${ }^{2} \&$ Shoaib Ali $^{3}$ \\ ${ }^{1}$ Lahore Business School, University of Lahore, Pakistan \\ ${ }^{2}$ LBS \& Bahria University, Pakistan \\ ${ }^{3}$ Air University, Pakistan \\ *Correspondence: Lahore Business School, University of Lahore, Pakistan. E-mail: Khawajaqau6@ yahoo.com
}

Received: August 1, 2017

Accepted: September 14, 2017 Online Published: October 25, 2017

doi:10.5430/mos.v4n4p12

URL: https://doi.org/10.5430/mos.v4n4p12

\begin{abstract}
Current study has been conducted to determine the factors those affect the internet banking adoption decision of banks in Pakistan. Logit Probit has been used to analyze the Panel data of twenty five banks in Pakistan, covering the financial year of 2006 to 2015. The results showed that six variables deposits, expenses, market share, spread and wages found significant association with internet banking adoption decision but others were found insignificant. Study found that most of the factors have affected the adoption decision of banking industry in Pakistan.
\end{abstract}

Keywords: banking; internet; financial services; virtual banking; Pakistan

\section{Introduction}

The advent of E-banking can be seen back in 1990, when very first digital banking facility was provided by Wells Fargo bank of California (Aggelis, 2005). Later on after few years bank located in USA named security First Network Bank, has started to provide full-fledged E-banking to its customer (Grandy, 1995). Today in most of the developed and developing countries financial institutes are providing digital banking facilities to their consumers (Lassar et al, 2005). Internet banking is very in-expensive, which is very important for growth and stability of the banks (Burnham, 1996). Like most of studies Shih \& Fang(2006) also said that E-banking is advance type of information system that uses internet WWW and other many advanced technologies.

Financial entities are now adopting automated services providers like, ATM (Automated Teller Machine), websites, mobile banking etc. Websites of the banks are very important because when detailed information regarding products and services will be available at their websites it will be easy for customers to choose and use the service. Because now a day's website plays a role of branch for customer, where customer visits the website instead of physical visiting the branch and communicates with the bank (Chaffey et al. 2006). Now in the whole world businesses are using electronic commerce to run their operations (Ahmed, 2006). Banks should altered their systems and procedures to the new technological environment in order to compete with digital world (Sadiq-Sohail \& Shanmugham 2003).

One of the major forces behind the changes happening to business today is technology, which is creating new products, services market opportunities and developing more information and system oriented business and management processes. Arrival of internet has provided many opportunities of drastic changes in the procedures and working of businesses. Banks are the service industry and they are information-intensive diligence so that's why they have been affected a lot by internet and advancement in information technology. It is also important to note that provision of internet services to whole economy affected the economy at both micro and macro levels. Researchers suggested that for the economic progress transmission of internet is necessary (Pilat \& Lee, 2001; Akhavein et al., 2001; Sullivan \& Wang, 2005).

A strong and dynamic banking system is very essential for economic development and growth of any country in the world (Economic Survey, 2013-14). Internet banking has affected and altered the way of businesses. Now customers are adopting the ways of online purchasing in developing countries like Pakistan, which is providing them variety of products and services. Technological advancement is not only providing efficient and speedy services, it also decreases the cost of businesses. Banking industry is one of the pioneer industries in adopting internet banking and it 
is very best for this sector (Kardaras \& Papathanassiou, 2001).

E-banking has changed the way of working in the financial sector by providing advanced and modern methods. Internet banking delivered better and quality services to ultimate consumer and get its benefits for long period of time. It is also important to mention here that E-banking is not a substitute of traditional way of banking but it can be differing from old banking in terms of quality services. Researcher also said that saving banks were among the early adopted of internet banking (Corrocher, 2002).

Research studies on financial innovations like (Akhavein, 2001; Apaka, 2012; Buzzacchi, 1995; Courchane, 2002; Nickerson, 2003). Most of the studies has analyzed the financial advancement through quantitative methods from recent studies like, (Bughin, 2001; Furst et al. 2000; Sullivan, 2000; DeYoung, 2005; Akhavein et al., 2001; Courchane et al. 2002; Hasan et al., 2002; Nickerson \&Sullivan, 2003; Sullivan \& Wang, 2005; Hannan \& Mcdowell, 1987). Some of the studies have analyzed the effects of internet banking, financial innovation and advancement on performance of banks like, (DeYoung, 2001, 2005 \& 2007; Nolle, 2007; Sullivan, 2000).

Due to modern era demand for internet banking has been increased, so that's why this topic has gained a lot of attention of researcher. But literature on internet banking mostly available in developed countries like USA, Italy, Turkey, Malaysia and many other European countries. In Pakistan most of the studies were conducted from customer's point of view and this study is first one which has focused bank's prospective in adoption decision. This paper has been divided in five sections; second section discusses the available literature on internet banking adoption. Third section provides data and explanatory variables and their expected results. Fourth section includes results and fifth section delivers findings of the paper.

\subsection{Significance}

The word "Internet-Banking" is now become very attractive in all over the world. But In Pakistan internet banking is still struggling for its growth. It has connected the whole world and a businessman wherever he is living can do his business transaction through these digital methods. Now the whole world is in competition, everyone wants to beat his rival by providing in-expensive and better services to expand his business (Lucking-Reiley\&Spulber, 2001).

Main rational behind this study is to analyze the factors those affecting the banks adoption decision of internet banking in Pakistan. Consistent with previous literature and to check these factors, some questions has been formed to check the effects of these factors on adoption decision. Practically this study will help to Banks to form their policy regarding Internet Banking adoption. Secondly, it will also helpful for State Bank of Pakistan to check and regulate the Internet Banking and make laws to enhance the Internet banking adoption process.

\subsection{Problem Statement}

In literature review a lot of studies have been found those analyzed the performance of banking industry and also check internet banking adoptability. But all of these studies focused on customer's preferences. To the best of my knowledge no one has analyze from bank's perspective in Pakistan. This study will analyze the effects of different factors like, deposits, expenses, market share, spread, wages, Age, Branches, ROA and size on adoption decision of Internet Banking of banks in Pakistan. So the problem statement is to determine the factors those affected the Internet Banking adoption decision in Pakistan.

\subsection{Objective}

Main purpose of this study is to check the influence of different factors like, deposits, expenses, market share, spread, wages, Age, Branches, ROA and size on adoption decision of Internet Banking of banks in Pakistan.

\section{Literature Review}

After the independence of Pakistan there was no proper banking system exist in the country. After that State Bank of Pakistan (Central Bank) has been established on $1^{\text {st }}$ july 1949 . Main functions of a central bank in a country to observe and control all the activities of banking sector and to also formulate policies, rules \& regulations for smooth working of banking sector in the country. So that's why State Bank of Pakistan also set guidelines in the name of prudential regulations to control, monitor and regulate the banking sector in the country (Hussain, 2006).

E-banking has changed the way of working in the financial sector by providing advanced and modern methods. Internet banking delivered better and quality services to ultimate consumer and get its benefits for long period of time. It is also important to mention here that E-banking is not a substitute of traditional way of banking but it can be differing from old banking in terms of quality services. Researcher also said that saving banks were among the early 
adopted of internet banking (Corrocher, 2002).

In Pakistan internet banking was introduced by foreign banks in 1990s. Firstly they have introduced ATM (Automated Teller Machine) and then credit, Debit cards was introduced. These products were new at that time and people in the big cities of Pakistan also demanded these products from domestic banks. So to remain competitive and in line with industry, domestic banks also invested in internet banking in 1990s (Shamim, \& Sardar 2010).

The last decade, especially the second half, is characterized by various advanced technological adoptions by banks, for example, E-Banking, Automated Teller Machines (ATMs), Credit Cards, M-net, Society for Worldwide International Facilitation Transfers (SWIFT), National Institutional Facilitation Technologies (NIFT), etc. The aim of adopting advanced technologies, despite bearing the heavy fixed cost for it, was to speed up the process of financial transactions through broad automated networking that resulted in low transaction cost per unit as well as customer facilitation in terms of fast human interaction.

In early 2000 Govt. of Pakistan has taken steps to link business, commerce and other social activities with internet. In these days commercial banks were leading the show by providing innovative and advanced products to its customers. Govt. of Pakistan also took initiative to make regulations for the adoption of these advanced technologies which helped the private as well as foreign banks to participate in the race of internet banking (Ahmed, 2006). When we talk about technological growth in Pakistan it is very sad to know that we cannot even compare technological growth of Pakistan with other developing countries. Technological improvement system is very slow in Pakistan (Khan \& Bawden, 2005).

To meet the technological demands of public and also for the speedy growth, seven IT specialized universities and one virtual university was established in Pakistan to produce more professional and qualified personnel. And continuation of these efforts has been found in our long-term education policy of 1998-2010. Main objective of this policy was to ensure that every student should learn about computer technology. Most of the foreign well reputed IT companies are also investing in our Information technology sector of Pakistan for the improvement and growth of this sector (Shahzada, 2006).

Pakistan is adopting internet banking in a speedy way (Shamim \&Sardar,2010). Due to the importance and increasing needs of internet banking it is also become very necessary to find out what the major factors those are forcing the banking industry of Pakistan to adopt internet banking. So that's why growing demands and importance of internet banking there are a lot of studies have been done to explore the forces which are forcing the banks to adopt internet banking.

Due to the importance and increasing needs of internet banking it is also become very necessary to found out what the major factors those are forcing the banking industry of Pakistan to adopt internet banking. So that's why growing demands and importance of internet banking there are a lot of studies have been done to explore the forces which are forcing the banks to adopt internet banking.

In Italy research concluded that internet banking is not a substitute to conventional banking but this new way of banking have feature of providing services in flexible ways. Saving banks were the pioneer in adopting internet banking services in Italy, only twenty percent were offering internet banking services in 1999 and most of them were larger banks among internet banking services provider. A small number of small banks were providing internet banking services. For internet banking provider main objective was not to earn a lot of money or yield there focus was just to capture new customers and to retain their existing base (Corrocher, 2002).

Results of the study described that there were small number of banks those were working efficiently by adopting internet bank services but most of them adopted both strategies (Sargua, Mehdianb \& Stoicaa, 2013). According to Giglio (2002) \& Robinson (2000), if a bank wants to deliver its products to its customer in an in-expensive way then online banking will be very best choice. Conventional banks showed a remarkable support for cost effectiveness and internet service provider were affecting Return on assets and Return on equity (Delgado, Hemando \& Nieto 2007). Internet banking is not a substitute it is become compulsory for a bank to adopt internet services if it want to remain in the market (Nolle, Lang \& DeYoung 2007).

Hanafizadeh, Keating \& Khedmatgozar, (2014) have studied different papers on internet banking and gives summary of research articles. They focus on past papers published from 1999 to 2012. IB adoption is very important advancement in banking industry and now become very interesting and popular topic in research. This will remain topic of interest in future. They have analyzed that data on IB adoption can be distribute in three categories Descriptive, Relational and Comparative. They have analyzed 165 articles and results indicated that IB will remain significant topic in future. In past relational studies were adopted by the researcher now research indicated that now 
focus will be shifted to comparative studies. They also examined that this study has been conducted in three region ASIA, EUROPE and AMERICA.

Internet Banking has positively affected the profitability of Banks in both developing and developed countries (Ilyas Akhisar, Batu Tunayb \&Necla Tunaya 2015). Positive relationship has been found between high profits and adoption decision. Banks those were generating high profits have adopted internet banking most due to retain their existing customers but they were not among the early adopters (Furst, Lang \& Nolle, 2000).

\subsection{Research Questions}

1. How Size, Age and Branch intensity of banks affect their decision to go for innovation?

2. Whether reduction in fixed expenses and Wages expenses attracted banking industry to go for digitalization?

3. What will be effects of ROA and deposits on internet banking adoption decision?

\section{Methodology}

\subsection{Data and Explanatory Variables}

Unit of analysis for this study is the Banking industry of Pakistan and twenty five banks have been included in the study which consists of Private, Public, Foreign and Islamic. We have taken only those banks which were established before or on 2006. Our sample is consisting on data ranging from 2006 to 2015. So that's why we have excluded some newly established banks and foreign banks those started their operations in Pakistan after 2006. Secondary data collected from Financial Statements, Annual reports of Banks and also from SBP's website in Pakistan for the period of 10-years. Logit Probit Model (in line with previously used by many other researchers) has been applied to check the effects of these factors on Internet banking adoption decision.

\subsection{Explanatory Variables}

First variable of interest is the AGE of a bank. According to the existing literature this variable expected to be negatively related with internet banking adoption decision. Because newly established banks easily adopt new and innovative products to increase their businesses and customer base, in comparison with old banks because they have legacy and traditional system and it is difficult to change or adopt new policy in these organizations. Because they have to face many obstacles during change process. (Ang \& Koh, 1997; Sullivan \& Wang, 2005) have used this variable in their research.

Second variable of interest is BRANCH intensity. This can also be a strong factor which has changed the direction of banking towards digital banking. Opening of new branch is very long and systematic process. There are opportunities for both those have large number of branches they can adopt internet banking as a measure to stop investing in opening of new branches by expanding their business through internet. Second those have less number of branches can take advantage of this modern technology because it is inexpensive way of expanding their businesses (Furst et. Al., 2001, 2002 Andriy 2001).

Third variable of discussion is DEPOSITS. Deposit is most important variable of banking literature, because banking without deposit is nothing. And without focusing on deposit we cannot complete our analysis on banks. Major and most important function of banks has to collect deposits. So we can say here that banks changes its policies and way of working to attract deposits. Andriy (2001) concluded in his study that deposits have positive effect on internet banking adoption decision.

Fourth factor which we have focused is EXPENSES. Expenses of fixed assets like furniture, building etc. By adopting internet banking expenses for fixed assets can be reduced. Internet banking is cheap enough as compared to traditional branch banking. So that's why it can affect the decision of internet banking adoption. But most of the researcher found no relation between internet banking adoption and reduction in fixed assets expenses. They also mentioned that during 2000s a remarkable expansion has been noted in number of bank branches in US (Nolle, Lang \&DeYoung 2006).

Another most important element of this study which we have to study is MARKET SHARE. Every business organization wants to increase their market share. Success of an organization can be measured through his market share in the industry. Most of the studies have suggested that expansion in market share of bank compel banks to adopt internet banking to retain their customer base (Courchane et al.., 2002).

Basic purpose of a commercial organization is to earn profit. All policies and regulations made in these organizations to increase their profits. So that's why earning can be a major factor which can affect the policies of organization. So 
that's why we have also select ROA variable to check its effects on decision making of banking industry in Pakistan. Most of profitable banks can go for internet banking because it can be helpful for them in two ways first of all it can help them to retain their profitability position and secondly financially strong banks can easily incurred expenses on internet banking. So that's why sign of effect is ambiguous for ROA whether it will affect the internet banking decision in Pakistan or not. Most of the studies have included this ROA factor in their studies in different countries to check its effect on internet banking decision and they have concluded that this factor has not affected the internet banking decision of banks (Bughin, 2001; Corrocher, 2002; Buzzacchi et al., 1995; Gourlay and Pentecost, 2005).

At number seven we have included SIZE factor to analyze its impact on internet banking adoption decision in Pakistan. SIZE can be measured as natural log of total assets. One research study has described that there is mindset that larger and big organization supports he changes in technology structure or in people due to their larger setups and economy of scale. Because larger and big organizations have mostly research \& development departments which help them to decide whether going for innovation will be beneficial for organization or not (Buzzacchi et al., 1995).

SPREAD is the gross profit for banking industry. Banks makes their policies to increase their interest income and also take measures to decrease their cost of fund and interest expenses. So when a bank will provide better services and products to its customers ultimately its customer base will be increased and his earning will be increased. So spread can be a major factor in deciding whether to go for internet banking or not. Most of studies have studied only ROA and ROE in their papers and tried to find out their relationship with internet banking adoption decision. So now we have also considered this important variable in our study and expecting a positive relationship with internet banking adoption decision by banks in Pakistan.

In last WAGES has been included in our model. Most of the studies has included because when an industry shifts its working from manual to computer we have seen a lot of reduction in their labor and personnel. Because computer can work more rapidly and accurately as compared to human. So when number of employees will be decreased in an organization ultimately wages will be reduced. So it can be a major factor which can attract banking industry to go for internet banking. Wages reduction has been found a major element to go for internet banking adoption in most of the countries (Hannan \& Mc Dowell, 1984; Sharma, 1993; Gretton et al., 2003; Sinha and Chandrashekran. 1992; Gourlay and Pentecost. 2005).

\subsection{The Model}

For the analysis of factors affecting bank's decisions of going for internet banking. Logit Probit can be estimated with the dependent variable of "INTERNET" which takes on a value of "1" if banks had adopted internet banking from 2006 to 2015, otherwise zero. A bank will be considered internet bank which has adopted internet banking by December 2015. Variables of the proposed model have been discussed in below.

Internet Adoption $=\beta 1_{\mathrm{i}}+\beta 2 \mathrm{Age}_{\mathrm{it}}+\beta 3 \mathrm{Bran}_{\mathrm{it}}+\beta 4 \mathrm{Dep}_{\mathrm{it}}+\beta 5 \mathrm{Exp}_{\mathrm{it}}+\beta 6 \mathrm{MS}_{\mathrm{it}}+\beta 7 \mathrm{ROA}_{\mathrm{it}}+\beta 8 \mathrm{Size}_{\mathrm{it}}+\beta 9 \mathrm{Spd}_{\mathrm{it}}+\beta 10 \mathrm{Wag}_{\mathrm{it}}+\mu_{\mathrm{i}}$ Where:

- $\quad \beta 1, \beta 2 \ldots \beta 10$ are the coefficients to be estimated;

- $\quad \mu_{\mathrm{i}}$ is a disturbance term

4.3.1 Dependent Variable:

Internet [Dummy for the Banks who have adopted Internet Banking by December 2015.]

4.3.2 Independent Variables:

Age [The Natural Log of The number of Years from the date of Incorporation to the last year of analysis. i.e. 2015].

Branches [The ratio of number of Branches to Total Assets].

Deposits [The ratio of Deposits to Total Funds].

Expenses [The ratio of expenses for premises and fixed assets to net operating revenue].

Market Share [Loans and Investments of Total Banks].

ROA [The ratio of average net profits to average assets].

Size [The natural Log of the total assets].

Spread [Log of Net Interest Income].

Wage [The ratio of Total Labor expenses to total number of employees]. 


\section{Findings}

\subsection{Table No.1}

Dependent Variable: INTERNET

Method: ML - Binary Logit (Quadratic hill climbing)

Date: 01/08/17 Time: 15:40

Sample: 20062015

Included observations: 250

Convergence achieved after 7 iterations

Covariance matrix computed using second derivatives

\begin{tabular}{|c|c|c|c|c|}
\hline$\underline{\text { Variable }}$ & Coefficient & Std. Error & z-Statistic & Prob. \\
\hline $\mathrm{C}$ & -6.788189 & 3.606639 & -1.882137 & 0.0598 \\
\hline AGE & -0.000594 & 0.005264 & -0.112829 & 0.9102 \\
\hline BRANCHES & 102.6183 & 161.0343 & 0.637245 & 0.5240 \\
\hline DEPOSITS & 7.640615 & 1.314560 & 5.812298 & 0.0000 \\
\hline EXPENSE & 0.564062 & 0.230883 & 2.443066 & 0.0146 \\
\hline MARKET & -19.22157 & 6.645914 & -2.892239 & 0.0038 \\
\hline ROA & 7.334165 & 7.860539 & 0.933036 & 0.3508 \\
\hline SIZE & -0.332031 & 0.557066 & -0.596034 & 0.5512 \\
\hline SPREAD & 0.747779 & 0.292702 & 2.554747 & 0.0106 \\
\hline WAGES & 0.001569 & 0.000621 & 2.527439 & 0.0115 \\
\hline McFadden R-squared & 0.304549 & \multicolumn{2}{|c|}{ Mean dependent var } & 0.760000 \\
\hline S.D. dependent var & 0.427940 & \multicolumn{2}{|c|}{ S.E. of regression } & 0.348775 \\
\hline Akaike info criterion & 0.846498 & \multicolumn{2}{|c|}{ Sum squared resid } & 29.19456 \\
\hline Schwarz criterion & 0.987357 & \multicolumn{2}{|c|}{ Log likelihood } & -95.81230 \\
\hline Hannan-Quinn criter. & 0.903190 & \multicolumn{2}{|c|}{ Restr. log likelihood } & -137.7700 \\
\hline LR statistic & 83.91537 & \multicolumn{2}{|c|}{ Avg. log likelihood } & -0.383249 \\
\hline Prob(LR statistic) & 0.000000 & & & \\
\hline Obs with Dep=0 & 60 & \multicolumn{2}{|c|}{ Total obs } & 250 \\
\hline Obs with Dep=1 & 190 & & & \\
\hline
\end{tabular}

Results of logit estimation are given in (table 1) in which first of all AGE has been listed. From table 1 we can see that coefficient of the variable is positive and insignificantly related to Internet banking. Here our hypothesis for Age has been rejected because these results indicate that older banks have adopted internet banking rapidly as compared to new banks. Because older banks had a suitable and large customer base. So that's why due to competitors pressure and technology advancement it compels old banks to adopt internet Banking to retain their existing customer base and also to capture new customers. Our results contradict with the findings of work done on internet banking adoption decision in India that new banks were offering internet banking services rapidly as compared to old banks (Malhotra, 2007). Another study also found no relation between AGE and internet banking adoption decision of banks (Delgado, Hemando\& Nieto 2007).

Second most important variable of the study was BRANCH intensity. We raised question mark on its effects because we were not clear about its effects. Now in the above results we can see that it is positively but insignificantly related with Internet adoption. It means that in Pakistan banks those have large number of branches they are still focusing on branch services as compared to Internet services. We can say that banks those have large number of branches not 
focusing on Internet Banking as key factor to serve the customer. And here we can also conclude that banks those have small number of branches are totally focusing on Internet Banking for attracting more customers. Internet banking is cheapest way of providing bank services to their customers Nolle, Lang, \& DeYoung (2006).

Third variable of our study was DEPOSITS, and in (table 1) results showed that DEPOSITS is positively and highly significant effected the Internet Banking adoption in Pakistan. This number shows that all banks whether they are small, big, private or public, have adopted Internet Banking as complementary for expansion of their deposits. In banking industry deposits plays very important role. Major functions of banking are to attract deposits from general public and sanction loans. Major source of earning of banking industry is the difference between deposit rate and lending rate. So when a bank will have strong deposit position definitely it will finance a large amount and will earn more profit. So that's why deposit is the blood for banking industry.

We can derive a conclusion from above discussion that Deposits played a vital and effective role in adoption of Internet Banking in Pakistan. These results regarding deposits are in line with the study conducted in India on internet banking adoption decision (Malhotra, 2007). But contradicts with the study conducted in US by Furst et.al.(2000).

Fourth variable of interest in our study was EXPENSES for fixed assets. Results of this variable are consistent with our hypothesis and positively related with Internet Banking. It means we can say that Banks see Internet Banking as a major factor to reduce their expenses for fixed assets. By adopting Internet Banking banks can reduce their costs for opening of new branches, fixing of fixed assets. Our results for EXPENSES are in line with the study conducted in India that reduction in fixed assets expenses is very major and attractive variable influence the adoption decision. (Malhotra, 2007).

MARKET SHARE was also key variable in determining the effects on adoption decision. Coefficient turns to be negative and in line with our assumption that Banks those have low market share are adopting Internet Banking rapidly to increase their market share in all segments. Because Internet Banking is very cheap and easy way to increase Market share of the bank. Our results are similar with the study of (Malhotra, 2007).

ROA (Return on Assets) variable included to check whether it has independent effect on Internet Banking adoption. According to the results this variable has insignificant relation with Internet Banking adoption. It means that this variable has not affected the decision of Internet banking adoption by Banks in Pakistan. We can also say that increasing in return was not primary objective of the Banks those have adopted Internet banking in Pakistan.

Next variable of discussion is SIZE; we assumed that this will be positively related with Internet Banking adoption decision. In our results it has negatively and insignificantly affected the Dependent variable. It is not in line with our hypotheses and it is also not matched with the study of Malhotra 2007. From above results we can say that small banks are not rapidly adopting and offering internet banking services as compared to larger banks.

Most important variable and factor for banking industry is Spread. Because it is Gross Profit of Banking Industry. We included this variable to check whether Internet banking adoption has been affected by this variable or not. We were not clear about its effects whether it will affect internet banking decision or not. Now according to the above results we can see that Spread is positively and highly significant related with the adoption decision. It means that banks those have high spread have rapidly adopted Internet Banking to decrease their expense and to increase their net income.

Last variable of interest was wages and it was hypothesis that this variable will positively affect the IB. Results of this variable are consistent with our assumption. It has positive and significant relation with internet banking adoption decision by banks in Pakistan. It means that if a bank has incurred a lot of expenses in personnel administration then it will encourage the banks to go for internet banking adoption as compared to those who have not beard these expenses.

\subsection{Descriptive Analysis: Pattern of Data Distribution}

In the (Table No. 2) pattern of data distribution has been calculated with the help of central tendency (Mean, Median, Maximum, and Minimum) and measures of dispersion (Standard deviation, Skewness, Kurtosis, Jarque-Bera, Probability, sum of squared deviation). To check the skewness of data the rule of thumb is that if it has positive values, data will be positively skewed and will be negatively skewed if it will pertain negative values. AGE, Branches, Expenses, Market, ROA Size and Wages are positively skewed while Internet, deposit and spread is negatively skewed. 
Table 2. Descriptive Analysis Table

\begin{tabular}{|c|c|c|c|c|c|c|c|c|c|c|}
\hline & INTERNET & AGE & BRANCHES & DEPOSITS & EXPENSE & MARKET & ROA & SIZE & SPREAD & WAGES \\
\hline Mean & 0.760000 & 36.752 & 0.000415 & 0.671440 & 1.554160 & 0.035923 & 0.007251 & 8.10340 & 6.492020 & 711.628 \\
\hline Median & 1.000000 & 21.000 & 0.000110 & 0.740000 & 0.505000 & 0.019675 & 0.008127 & 8.20500 & 6.676000 & 628.640 \\
\hline Maximum & 1.000000 & 203.00 & 0.020000 & 0.910000 & 176.4700 & 0.154840 & 0.371871 & 9.35000 & 7.885000 & 3077.07 \\
\hline Minimum & 0.000000 & 0.0000 & 0.000000 & 0.030000 & -2.950000 & 0.000200 & -0.316204 & 6.60000 & 0.000000 & 0.00000 \\
\hline Std. Dev. & 0.427940 & 40.130 & 0.001944 & 0.204757 & 11.16356 & 0.040941 & 0.037830 & 0.63172 & 1.166620 & 401.340 \\
\hline Skewness & -1.217562 & 2.6303 & 8.156684 & -1.637470 & 15.47997 & 1.473853 & 1.503650 & -0.35123 & -3.520855 & 1.83501 \\
\hline Kurtosis & 2.482456 & 10.889 & 73.36429 & 4.922542 & 243.0239 & 4.183905 & 59.76279 & 2.28534 & 20.03591 & 8.54652 \\
\hline Jarque-Bera & 64.55913 & 936.72 & 54346.45 & 150.2229 & 610104.2 & 105.1105 & 33656.86 & 10.4604 & 3539.667 & 460.760 \\
\hline Probability & 0.000000 & 0.0000 & 0.000000 & 0.000000 & 0.000000 & 0.000000 & 0.000000 & 0.00535 & 0.000000 & 0.00000 \\
\hline Sum & 190.0000 & 9188.0 & 0.103700 & 167.8600 & 388.5400 & 8.980790 & 1.812748 & 2025.85 & 1623.005 & 177907.0 \\
\hline SumSq. Dev. & 45.60000 & 400994.00 & 0.000941 & 10.43948 & 31031.63 & 0.417365 & 0.356347 & 99.3686 & 338.8893 & 4010736 \\
\hline Observation & 250 & 250 & 250 & 250 & 250 & 250 & 250 & 250 & 250 & 250 \\
\hline
\end{tabular}

Jarque-bar test follows the Chi-Square distribution pattern to check the distribution pattern of the data. Null hypothesis of jarque-bar test is data is normally distributed. If the value of JB test tends more towards Zero, null hypothesis will be rejected. It can be derived from above presented results in the table that except one variable no one was normally distributed. So that's why mathematical transformation was required. In this study Internet was Dependent variable was transformed to dummy variable by assigning them 1 and 0 .

The ideal value of Kurtosis should be equal to 3. And most of the observations have the values of more than 3 . When values falls in more than 3 it means most of the values falls in the tails of normal curve. When data falls in the tails of normal curve then problem of outlier increase so that's why through transformation of dummy variables this problem will be reduced.

\subsection{Correlation}

Table 3. Correlation Table

\begin{tabular}{|c|c|c|c|c|c|c|c|c|c|c|}
\hline & AGE & BRANCHES & DEPOSITS & EXPENSE & INTERNET & MARKET & ROA & SIZE & SPREAD & WAGES \\
\hline AGE & 1 & & & & & & & & & \\
\hline BRANCHES & 0.024046 & 1 & & & & & & & & \\
\hline DEPOSITS & -0.18337 & 0.008933 & 1 & & & & & & & \\
\hline EXPENSE & -0.06345 & -0.0089 & -0.04602 & 1 & & & & & & \\
\hline INTERNET & -0.06194 & 0.031994 & 0.470998 & 0.031516 & 1 & & & & & \\
\hline MARKET & 0.177007 & 0.10607 & 0.356972 & -0.07342 & 0.057677 & 1 & & & & \\
\hline ROA & 0.13491 & 0.031982 & 0.00998 & -0.03366 & 0.124997 & 0.186405 & 1 & & & \\
\hline SIZE & 0.099089 & 0.087777 & 0.477737 & -0.12696 & 0.183082 & 0.780868 & 0.174993 & 1 & & \\
\hline SPREAD & 0.15614 & 0.071631 & 0.199431 & -0.24387 & 0.229715 & 0.505237 & 0.41506 & 0.592189 & 1 & \\
\hline
\end{tabular}

From (Table No.3) we examine that AGE and Branches have positive relationship, it means that by increasing the age of banks no. of branches has been increased. Branches and deposits have also a positive relationship this indicates that expansion in number of branches have positive effect on deposits of the banks. When branches will be increased it will cause to increase the deposits of banks. Deposits and expenses has negative relationship. Expenses and Internet expansion has positive relationship. Internet and market share also have positive relationship it means that by increasing the Internet based transactions and products Market shares of the banks has been increased. It indicates that Internet Banking has played a major role to expand the Market share of the banks. We can say that it is a major factor which have compelled the banks to adopt Internet Banking. Market share also have positive relationship with ROA it means that when Market share of the banks will be increased it will increase the Return on Assets. ROA has positive relationship with size that means ROA will be increased by expansion in the size. Internet has only negative relationship with the AGE this indicates that older banks were reluctant to adopt Internet Banking 
as compared to newly established business.

\section{Conclusion}

Main objective of the study was to investigate the impact of different factors on internet adoption decision of banks in Pakistan. Logit probit model has been used to analyze the panel data collected from the financial statements of banks. In Pakistan older banks adopted internet banking rapidly as compared to new established. Branch intensity factor does not affect their adoption decision. So here we can say that banks those are older, having high spread, having remarkable market share, want to decrease their expenses and to expand their deposits was much interested in internet banking as compared to newly established banks.

One of the major limitations of this study is scope and size of its variables. We have included deposit, expenses, size, age, market share and different other factors in our study. But we have not included other many factors like ownership structure and their effects on internet banking adoption decision. This can be a major factor in this segment because in public sector banks in Pakistan old legacy system exists and it can be major restriction in adoption of internet banking. This study can be helpful in policy formation regarding digitalization of banking industry in Pakistan. This study can also helpful for Bank's management for making decisions about adoption, innovation and expansion of internet banking in Pakistan.

\section{References}

Ariff, M. S. M., Yun, L. O., Zakuan, N., \& Jusoh, A. (2012). Examining dimensions of electronic service quality for internet banking services. Procedia-Social and Behavioral Sciences, 65, 854-859. https://doi.org/10.1016/j.sbspro.2012.11.210

Akhavein, J. D., Frame, W. S., \& White, L. J. (2001). The diffusion of financial innovations: An examination of the adoption of small business credit scoring by large banking organizations. (March 2001). NYU Working Paper No. EC-01-08. https://doi.org/10.2139/ssrn.267681

Apak, S., Tuncer, G., Atay, E., \& Koşan, N. İ. (2012). Insights from knowledge management to radical innovation: "Internet banking applications in the European Union". Procedia-Social and Behavioral Sciences, 41, 45-50. https://doi.org/10.1016/j.sbspro.2012.04.006

Apak, S., \& Atay, E. (2012). Eurozone debt crises versus new opportunities for global internet banking collaboration and strategic alliances in the EU and Balkan countries. Procedia-Social and Behavioral Sciences, 58, 560-568. https://doi.org/10.1016/j.sbspro.2012.09.1033

Atay, E., \& Apak, S. (2013). An overview of GDP and internet banking relations in the European Union versus China. Procedia-Social and Behavioral Sciences, 99, 36-45. https://doi.org/10.1016/j.sbspro.2013.10.469

Andriy, C. (2001). ELECTRONIC BANKING IN UKRAINE: THE FACTORS IN DECISION-MAKING (Doctoral dissertation, National University of Kyiv-Mohyla Academy).

Bughin, J. (2001). E-pull or e-push? Laggards and first-movers in European banking. Journal of Computer Mediated Communications, 7(1). https://doi.org/10.1111/j.1083-6101.2001.tb00133.x

Bughin, J. (2003). The diffusion of Internet banking in Western Europe. Electronic Markets, 13(3), $251-258$. https://doi.org/10.1080/1019678032000108329

Bughin, J. (2004). The success of Internet banking: an econometric investigation of its pattern of diffusion within Western Europe. Katholieke Universiteit Leuven,[Faculty of Economics and Applied Economics], Department of Applied Economics.

Buzzacchi, L., Colombo, M. G., \& Mariotti, S. (1995). Technological regimes and innovation in services: the case of the Italian banking industry. Research Policy, 24(1), 151-168. https://doi.org/10.1016/0048-7333(93)00756-J

Colombo, M. G., \& Mosconi, R. (1995). Complementarity and cumulative learning effects in the early diffusion of multiple technologies. The Journal of Industrial Economics, 13-48. https://doi.org/10.2307/2950423

Corrocher, N. (2002). Does Internet Banking Substitute Traditional Banking?: Empirical Evidence from Italy. Università commerciale Luigi Bocconi.

Courchane, M., Nickerson, D., \& Sullivan, R. (2002). Investment in internet banking as a real option: theory and tests. Journal of Multinational Financial Management, 12(4), 347-363. 
https://doi.org/10.1016/S1042-444X(02)00015-4

Delgado, J., Hernando, I., \& Nieto, M. J. (2007). Do European primarily Internet banks show scale and experience efficiencies? $\quad$ European $\quad$ Financial $\quad$ Management, $\quad 13(4), \quad 643-671$. https://doi.org/10.1111/j.1468-036X.2007.00377.x

DeYoung, R. (2001). The financial performance of pure play Internet banks. Economic Perspectives, 25(1).

DeYoung, R. (2005). The performance of Internet-based business models: Evidence from the banking industry. The Journal of Business, 78(3), 893-948. https://doi.org/10.1086/429648

DeYoung, R., Lang, W. W., \& Nolle, D. L. (2007). How the Internet affects output and performance at community banks. Journal of Banking \& Finance, 31(4), 1033-1060. https://doi.org/10.1016/j.jbankfin.2006.10.003

Daneshgadeh, S., \& Yıldırım, S. Ö. (2014). Empirical investigation of internet banking usage: The case of Turkey. Procedia Technology, 16, 322-331. https://doi.org/10.1016/j.protcy.2014.10.098

Furst, K., Lang, W. W., \& Nolle, D. E. (2000). Who offers Internet banking?. Journal of Financial Services Research (2002), 22, 95. https://doi.org/10.1023/A:1016012703620

Furst, K., Lang, W. W., \& Nolle, D. E. (2001). Internet banking in the US: Landscape, prospects, industry implications. Capco Institute Journal of Financial Transformation, 2, 45-52.

Furst, K., Lang, W. W., \& Nolle, D. E. (2001). Internet banking: developments and prospects. SSRN Electronic Journal.

Gourlay, A. R., \& Pentecost, E. J. (2005). The impact of network effects on technology adoption: evidence from the adoption of automated teller machines. Department of Economics, Loughborough University, Loughborough.

Hannan, T. H., \& McDowell, J. M. (1984). The determinants of technology adoption: The case of the banking firm. The RAND Journal of Economics, 328-335. https://doi.org/10.2307/2555441

Hannan, T. H., \& McDowell, J. M. (1987). Rival precedence and the dynamics of technology adoption: an empirical analysis. Economica, 155-171. https://doi.org/10.2307/2554388

Hanafizadeh, P., Keating, B. W., \& Khedmatgozar, H. R. (2014). A systematic review of Internet banking adoption. Telematics and informatics, 31(3), 492-510. https://doi.org/10.1016/j.tele.2013.04.003

Keeton, W. R. (2001). The transformation of banking and its impact on consumers and small businesses. Economic Review-Federal Reserve Bank of Kansas City, 86(1), 25.

Nickerson, D., \& Sullivan, R. J. (2003). Financial innovation, strategic real options and endogenous competition: theory and an application to Internet banking. Federal Reserve Bank of Kansas City Payments System Research Working Paper PSR WP, 03-01.

Purwanegara, M., Apriningsih, A., \& Andika, F. (2014). Snapshot on Indonesia regulation in mobile internet banking users attitudes. Procedia-Social and Behavioral Sciences, 115, 147-155. https://doi.org/10.1016/j.sbspro.2014.02.423

Santouridis, I., \& Kyritsi, M. (2014). Investigating the determinants of Internet banking adoption in Greece. Procedia Economics and Finance, 9, 501-510. https://doi.org/10.1016/S2212-5671(14)00051-3

Sharma, S. (1993). Behind the diffusion curve: an analysis of ATM adoption. Ssrn Electronic Journal, 1510(1-2), $152-166$

Sullivan, R. J. (2000). How has the adoption of internet banking affected performance and risk in banks?. Financial Industry Perspectives, 1 .

Sohail, M. S., \& Shanmugham, B. (2003). E-banking and customer preferences in Malaysia: An empirical investigation. Information sciences, 150(3), 207-217. https://doi.org/10.1016/S0020-0255(02)00378-X

Sullivan, R., \& Wang, Z. (2005). Internet banking: An exploration in technology diffusion and impact. Federal Reserve Bank of Kansas City Payments System Research Working Paper, 05-05.

Serener, B. (2016). Statistical Analysis of Internet Banking Usage with Logistic Regression. Procedia Computer Science, 102, 648-653. https://doi.org/10.1016/j.procs.2016.09.456

Takieddine, S., \& Sun, J. (2015). Internet banking diffusion: A country-level analysis. Electronic Commerce Research and Applications, 14(5), 361-371. https://doi.org/10.1016/j.elerap.2015.06.001 


\section{Other References}

Gujrati, D.N. (2004), Basic Econometrics, 4th ed., Tata McGraw-Hill, New Delhi.Lea, M. (1996), "Innovation and the cost of credit: a historical perspective”. Housing Policy Debate, 7(1), 147-74.

Banking sector reforms by Ishrat Hussain. Journal of political economy, 106(5), 2006. 


\title{
The CEO's Managerial Skills, Ups and Downs of a Firm and Crisis
}

\author{
Alexandru Trifu ${ }^{1, *}$ \\ 1،"Petre Andrei” University, Iasi, Romania \\ *Correspondence: "Petre Andrei” University, Iasi, Romania. E-mail: trifu.alex@ gmail.com
}

Received: October 2, 2017

Accepted: October 24, $2017 \quad$ Online Published: October 28, 2017

doi:10.5430/mos.v4n4p23

URL: https://doi.org/10.5430/mos.v4n4p23

\begin{abstract}
We are dealing in this paper with the general issue of management crisis, crisis as inflection and disturbing point for the economic entity. There many causes for the appearance and ongoing of crisis within socio-economic systems. We chose the most important cause: that of the action and decision-making of the outstanding human resource and propeller for the entire activity, the CEO.

Starting from Peter Drucker's allegation that the CEO is the power-link between the organization and the business/natural environment, we want to highlight that the plans, the ideas, and intentions of a CEO dedicated and efficient lead to efforts and costs inside the entity and results (bad or good) outside, into society and markets. The CEO is main person to see, to predict, the opportunities for the performance of the company. BUT, the results can be favorable on medium run, or only on short run, involving possible subsequent crisis, consisting on undulating movements of the entity activity.

Specifically, we propose the situation of John Reed, former CEO of Citicorp (then Citigroup), in fact the architect of the complex mega-financial structure which became Citigroup and negative repercussions occurred from factual financial activity of the corporation.
\end{abstract}

Keywords: crisis; CEO; skills; experience; financial supermarket; profit; consumers' satisfaction

\section{Crisis Management-an Approach}

The crisis management, by its characteristics and consequences, derogates from the rules set. For example, the crisis is considered as "an event, or set of circumstances, threatening the integrity, the reputation, or the very existence of the individual or organization (....), and the potential losses for the entity are considerable" (Sapriel, 2003).

Barry McLonglin, in a same approach, defines the crisis as being "an event, disclosure, accusation (...) threatening the integrity, reputation and the existence of people and of organization” (McLonglin, 1996).

The field of crisis management is considered starting with famous Johnson \& Johnson situation of 1982, when a cyanide-laced Tylenol killed seven people in the Chicago area. The reaction was prompt, capsules were recalled and the counteroffer was free product in tamper-proof packaging. This quickly swift led to a minimum lose for shareholders and the brand and the production recovered, continued and flourished (Wigmore, 2013).

Imagine the entity, the socio-economic system of it, as human body! And, exactly as in the physiology, they might appear moments of malfunction of different components of the system, pain crisis, negative aspects which might lead to worse the operating system. It is the climax which has to be solved immediately, using different straight and firm actions, in order to restore the proper functioning of the body as a whole.

The same it is the situation within an entity, regarding its management and well-functioning of all components (compartments, divisions, offices). The crisis management can be seen as the application of tactics and strategies designed to help the whole entity (organization) to deal with a sudden and significant negative event occurred (our emphasis).

A crisis occurs, in the quasi-majority of cases, in the ascending curve of the activity and performance of an entity (firm, organization) as a result of an unpredictable event (of endogenous, or exogenous nature), or as a consequence less predictable of an event considered a potential risk (in the risk portfolio of actions and events). 
Patrick Lagadec considers that, sometimes, there are no signs of onset the crisis and there are interim periods which can lead (Chiciudean, Tones, 2002), step by step, to the imminent and disastrous crisis (Lagadec, 1993).

Speaking about crisis in the firm's organism (system), this inflection point in the functioning of the system requires that decisions to be made quickly, by determined and skillful managers (CEOs), in order to limit the damages and perturbations to the firm or organization. A good manager is that one who is prepared to cope with crisis and, more of it, to solve favorably the inconvenient occurred. This situation, because the management and economic practice tell us that the costs are inside the firm (organization, corporation...) and the results (including the feedback process) is on the markets, in communities.

Starting from what Peter Drucker said in 2004 that is the CEO is the link between Inside (organization) and Outside (the economy, society, customers), the CEO is doing for Outside, BUT with the Inside support. The development and sustainable growth (the quantitative aspect of the functioning of a firm) of the institution is the CEO's main responsibility and even legacy (Lafley, 2009).

Furthermore, we can mention (Bertrand and Schoar, 2003) who presented the heterogeneity regarding the CEOs' profiles and abilities, consisting in differences in the level of education, work experience (including the experience in the relationships with staff, employees, people), main traits of character and of personality. Hence, the differences in corporate policies (strategies and tactics) and the performances and value of the corporation (firm, organization)

Therefore, in this paper, we will use the inquiry method, analyzing a management crisis, starting from an entity, a financial one and, mainly, the CEO's activity as core of the human factor of production, who that may influence the status and the future of the corporation. Collecting correct and important data, following the movements on the market and a sense of forecasting, these are the structure elements to determine the possibilities of risks and of an imminent crisis. In many situations however, a crisis had not a catastrophic character.

We focused on a CEO's activity, because this person is the only one to be oriented towards performance and the results of the company (firm, organization), accordingly to the goals of the entity, but also with the standards, regulations and behavior/intentions of stakeholders.

We think that in such cases of crisis, the best practices include, primarily, the existence of programs to be followed (even reserve plans, the well-known plan B...) and procedures to detect early signals of any foreseeable crisis, engaging the team and even stakeholders in these plans.

Also, we may speak about the application of the Murphy Law in this situation, because bad aspects (things) happen, even in the cases when persons like CEOs, for example, have done their best in the interest of the firm, to protect it and the employees.

Integrating the outside and the inside aspects is very hard to do. And the following case demonstrates just that.

* As the methodology, in this paper we took into consideration the analysis of a specific case (event, aspect) and, therefore, by induction to understand the role of a CEO who, using his abilities and skills, to determine the non-linear, but waving operations of the entities, with ups and downs. Also, we used the method of positivism, a philosophy considering that the research on observable and analysis of social economic realities are best for generalization.

Bryman \& Bell (2015), besides positivism (Bryman, 2015), say that inductive method is the best form for qualitative researches, including the highlighting of the managerial behavior and actions within a corporation (firm).

\section{The CEO John Reed and Citigroup}

Our intention is only to outline in few words a prodigious and fruitful activity and performing management of a person, identifiable person with the very CEO. In a word, as John C. Fillmore campaign slogan in presidential elections in U.S.A. 1856 enunciates: the right man for the right place (Currier, 1856).

We start with the best possible assessments about his person and his capability to run the future giant-created, Citigroup. First of all, he is known for the introduction and large-scale banking utilization of ATM (Automatic Teller Machine) and credit cards (instead of cash, checks, or other payment modalities paper-based on). The new modalities of financial operations (at that time) and the opening to the consumers' banking needs, allowed Reed to provide the foundation that made Citicorp one of the world pre-eminent consumer bank.

As CEO at Citicorp, let's say, the first stage of the future financial giant or conglomerate Citigroup, in fact a financial behemoth, John Reed was the person who managed the company very well in troubled times (the 90's of the last century), registered in his normal daily routine the alternation between the inner reflection and the numerous social 
interactions. In this respect, John Reed himself said that from 5 a.m. until 9, 30 or 10 a.m., it's the time for preparing quietly the program for the day (including detailed lists with problems and targets to be reached), and after that, begins the interactions with people from inside and outside the firm. As CEO of a large company, you're also a tribal leader, meaning that people permanently come to talk and advise you (Csikszentmihalyi, 2007).

But, on the other hand, his activity as a CEO, as a skillful and experienced manager is not alike with the term of "workaholic person", which means a compulsory and pathologic work, a forgetfulness of the pleasures and beauty of life. John Reed succeeded to work hard and efficient and to have time for other pleasant activities which contribute to improve the quality of life (Csikszentmihalyi, 2007).

He was considered a remarkable person, with many skills and abilities in the field, no hands-on manager for many years of the effective leadership as a CEO, but with negative aspects consisting in changing over the years of the senior managers and, by compensation, an inability to trust and work efficiently with his staff (O’Brien, 1998).

In the analyzed case, we cope with crisis of skewed management values, we are saying so, from the classification of management crisis, because the direction to be followed was the enlargement and enrichment, the appetence of what the CEO lusted in his vision of becoming, neglecting ongoing the stakeholders and broader social values. And, in the following stages of functioning and existence of the corporation, it was noted the trend to disregard the interests of other categories of stakeholders such as clients, employees and community.

In any event occurred, John Reed succeeded to survive the uncertainty of the early 90's (a first major descending curve, wave) and, much more, sustained and repositioned Citicorp for at least 6-7 years to become one of the most profitable and reliable bank of the world, and for real, in couple of decades, the most international of US banks.

And, another strength point for John Reed is the Machiavellian leader skills (face to production and toward obtaining profit and power), because he lacked in the social acumen and in the work with collaborators and own executives.

As a partial conclusion, in order to understand the actions and the facts of John Reed and of Citicorp, later Citigroup, we may say that he was a very skillful and determined top manager, using his brain and extensive knowledge, both in the financial domain and in general culture to give more power to his entity, to enrich it (and himself) and to prove his managerial ability to run a business on a large scale. "He is a very remarkable person, but by the standards of you and me he lives on another planet", said a former senior executive of Citicorp in this respect.

All in all, John Reed remains as a brash, very chancy, very vintage manager of his time (O'Brien, 1998). He intended to proof his capabilities, his knowledge, maybe in a race of his own, in order to gain, including the entity who was leading, neglecting medium to long run evolution.

\section{Managing Crisis Resolution}

In the presence of this huge entity of financial nature and structure, the problems emerged from the interior, from the actions and decisions-made by the CEO. We are not, in this case, in the presence of direct impact of products on people or environment (see the famous cases Tylenol or Exxon), but in the situation of a financial organism which grew and enlarged its dimensions, even by merger and including different complementary financial institutions in its composition (Davis). The merger with Travelers Group Inc. was the wrong action and the starting point for the descending curve (the involution) in the functioning of Citigroup, a very daring venture. This merger, the biggest transaction in the history, until the end of 20th century, for a sum of $\$ 70$ billion dollars and was the success of the audacious plan thoroughly thought by John Reed.

Later, John Reed affirmed that putting together Citi and Travelers we created (him and Weill) a monster. And, of course, we agree with Reed, that the most difficulties were occurred (met) from the Salomon Brothers side" (Martens, 2015), a very important and inconvenient player on the market. One of the a priori most important issues foreseen by the CEOs was the bringing together of two different organizational cultures, not entirely incompatible, but regarding two complementary and distinctive financial activities.

Sanford "Sandy" Weill ("the bad boy" CEO of Travelers and Reed have developed financial ingenious schemes for the development of the new entity, but for the most part, in their own profit. The result, the near one, was the making out of shareholders and the enriching of them: primarily for Weill, but also for Reed (for example, in the A.D. 1997, Reed owned stock and options, currently valued at minimum $\$ 272$. mil. of dollars).

In sum, Weill was principal right in one aspect: both he and Reed became "so rich", even the company was in decline. Primarily, by merging with Travelers, the new established corporation, the Citigroup, tried to offer for their consumers' 
satisfaction all over the world, banking, mutual funds, brokerage insurance services under the same roof, in one giant financial unit.

The Citigroup, so accomplished, is based on a model of a "financial supermarket", with one single stop for customers to solve all financial issues.

Citigroup was considered, at the beginning of the Millennium (and after the John Reed departure and his 4.7 million shares selling), the weakest of the of the big-five Wall Street institutions but its strengthening earnings and sale of non-core assets allowed it to become the first to report a double-digit capital ratio under the new Basel III standards.

The artisan of the later strengthening and favorable situation of Citigroup is considered Mike Corbat, who led this huge entity, in 2007, in its best half-year earnings for 6 (six) years (Braithwaite, 2013). But, over the period 2000-2011, the general aspect regarding the earnings of shareholders has shown a drastic decrease (almost a decimation of value) cu 88\% in 2011 compared to 2000 (April 18, when John Reed stepped down, with 100 shares valuing \$6,212-by comparison, in 2011, the same 100 shares worth $\$ 729.82$ ).

The selling of a large amount of shares $\$ 4.7 \mathrm{bn}$, after 2010 , has represented another good financial shot in order to increase the performance of Citigroup, in what Mike Corbat said that is "the largest percentage reduction of assets since 2010" (Braithwaite, 2013).

Another up and down occurred in 2008, in fact a crash during the Great Depression during the first decade of the new Millennium and again John Reed was in the middle of Citigroup media impact, admitting, once again, that the creation of this mega financial structure which is Citigroup was a bold, but terrible idea, in what its "creator" compared the entity, as we saw, with a financial supermarket (all components, "stores", being from the same domain).

Much later (2010 for precision), not only John Reed recognized that he created a "monster" by Citigroup merger, but also media define him as being dead wrong in the drawing of this financial mega-entity (Martens, 2015).

An aspect which has to be brought in attention is the relationship between this mega financial entity and State regulations. More precisely, we speak about John Reed's managerial success in breaking down the Glass-Steagall Act (in force from the Great Depression 1929-1933). It was no collusion between Government and Corporate entity in this case, the removal of the Glass-Steagall Act facilitating the merger between the two mentioned corporations. Furthermore, Bill Moyers highlighted that the merger Citicorp and Travelers, from one side and a so-called Presidential pen, on the other hand, brought down the above mentioned Act, considered a firewall between banks and investment firms which had protected consumers from financial losses. On his turn, John Reed, several years earlier, evoked the protectionist character of the Act, if not in its intent, but in its consequences and since then, he sprouted the idea of removal this regulation for personal benefit (for him and his firm). The Clinton Administration, exactly by President's pen, obligingly repealed the Glass-Steagall Act one year after the above-mentioned merger.

\section{Results}

From all written sources consulted, including the own opinions of the involved CEOs in the problem (much more of John Reed's), it is clear that the premonitions, based on knowledge, skills, business flair, in respect of John Reed, were confirmed in the last decade of $20^{\text {th }}$ century, in that represented by financial organizations, having as core a commercial bank, which are capable to integrate investment banks, insurance company, will dominate the global market at the beginning of $21^{\text {st }}$ century, making the leap from a so-called balkanized system (referring to USA in the early 90 's) to post-modern and futurist financial entity.

The inquiry showed us the importance of a CEO's actions, his will and administrative good organization of the work, towards reaching a better place on the specific market and to survive, by continuing its activity and designation.

In fact, the feature that we intended to emphasize was that of CEO tenure on medium run for one person and, by consequence, the evolution of the activity of the respective entity, and possible avatars in its existence and functioning.

More of that, the model of John Reed, in its main features, was appropriated by other manager and CEOs. And this aspect appeared due to the fact that, as we know, the financial (capital) market is the most sensitive and risky market and it was necessary to find people with the required skills and know-how to manage the difficulties of the firms.

Due to the fact that the life cycle of a firm, corporation, follows exactly the curve of the business cycle, we think that, in this specific case, we are not in the presence of $\mathrm{U}$-shape evolutionary curve.

We have reached to the results of a CEO's activity and of his appointment through empirical studies and observations (Limbach, P. et al., 2015) including in this category, for example, the downfall of a private university to the medium 
run mismanagement of its rulers (i.e., do not count the existence and goal of the entity, important was the welfare and prosperity of rulers).

\section{Conclusions}

Each organizational activity, we may say that, is unique. Therefore, it is quite impossible to offer general solutions and even scenarios for managing crisis, only general directions, plans and measures, in order to flat the crisis' impact and recover, in good parameters, the entity activity. The situation is not quite black or white. To deal with the crisis can be learned from books, papers, courses, but merely taking into account the abilities to notice and understand the details, intuition, of the managers, or of the team called to solve the situation.

In our case, we are dealing with the activity and decision-making process of the most important human resource of a corporate entity: the CEO and outstanding stakeholder at the same time. The decisions taken by the CEO of the Citicorp, then of the Citigroup and ultimately of the conglomerate including by merger Travelers were in accordance with the excellent expertise of him, the capacity to understand the mechanisms and actions from the financial markets and, at the same time, with his desire to enlarge the power of the corporation.

For real, John Reed in his developing and ascending period was a "prince" of the Wall Street, but the deal with Travelers was the fine action in order to impose the supremacy, a forward thinking, in terms of banking production and geographic strategy (a very break-out and audacious goals planned, correctly executed the merger and the entire financial re-positioning in the financial services industry, as warned in due time, Judah Kraushaar from Merrill Lynch).

It is the situation in which, human intuition, experience, skills, are responsible both for triggering crisis (financial, in our study), but also for the measures taken, along some future periods of time, in order to reduce and eliminate the crisis effects. These traits are necessary, both for corporation and for clients/business environment.

The organization is capable, by itself, both through internal mechanisms (see the capabilities and skills of CEOs and other top managers or leaders) and external (the signals from the feedback process on the specific market) to respond, on short term, or medium to long term (as this case is) to crisis that may occur in its work and functioning. In fact, the agitated history of Citigroup, with scandals, bailouts, important losses for its shareholders, was a permanent challenge (a permanent source of crisis, we may say) for all parties involved in the field (supporters or opponents of the virtues of a global banking system).

The strategy high risk, the bringing together of several financial institutions in one huge unit, was the main cause of the collapse of Citigroup, BUT the tactics imposed and followed by audacious CEOs led to a temporary recovery of the activity, ensuring that undulation of the functioning that I have mentioned (prosperous periods-good management, disastrous periods-poor management, like that of Chuck Prince).

In the case described above, we had to deal with a corporation (an entity) which survived decades of existence, having as CEOs professional and dedicated persons in the financial field. Hence, its cyclical activity, each time, in the difficult times (of crisis), suitable managers appeared, at the proper time and place, in order to save the organization and to continue to be in the benefit of communities. Of course, it should be not forgotten the regulatory action of the State, either in the respect of a new Act Glass-Steagall type, or even the removal of Government subsidies, still operating by the financial hyper-units.

The final idea is that regarding the period of ups and downs in the firm's life cycle, especially downs and on medium-term, trend leading in many cases to insolvency and in other cases, uniting endogenous with exogenous factors, the respective entity is recovering and records increases.

\section{References}

Bertrand, M., \& Schoar, A. (2003). Managing with style: The effect of managers on firm policies. Quarterly Journal of Economics, 118, 1169-1208. https://doi.org/10.1162/003355303322552775

Braithwaite, Tom. (2013). Citigroup recovery under Mike Corbat, boosted by strong trading, in Financial Times. Retrieved August 30, 2017 from www.ft.com/content

Bryman, A. (2015). Social research methods. Oxford University Press.

Bryman, A., \& Bell, E. (2015). Business research methods. Oxford University Press. 
Chiciudean, Ion \& Țoneş, Valeriu (2002). Gestionarea crizelor de imagine (The image crisis management). Comunicare.ro, Bucharest.

Csikszentmihalyi, Mihalyi. (2007). Starea de flux (Findings Flow. The Psychology of Engagement of Everyday Life). Curtea Veche Publishers, Bucharest.

Currier, Nathaniel. (1856). The right man for the right place, lithography. Retrieved September 3, 2017 from www.loc.gov/pictures

Davis, Marc-Crisis Management Strategies for Business Owners. Retrieved September 2, 2017 from www.investopedia.com/articles/financial-theory

Lafley, A. G. (2009). What only the CEO can do. Harvard Business Review. Retrieved November 28, 2016 from www.hbr.org/2009

Lagadec, Patrick. (1993). Preventing Chaos in a Crisis-Stretegies for Prevention, Control and Damage Limitation (English version). McGraw-Hill Book Company, London.

Langley, Monica. (2003). Tearing Down the Walls: How Sandy Weill Fought His Way to the Top of the Financial World..., Wall Street Journal Books.

Limbach, Peter et al. (2015). Do CEOs Matter? Corporate Performance and CEO Life Cycle. Swiss Institute of Banking and Finance, School of Finance Working Papers, p. 1-6.

Martens, Pam \& Russ. (2015). John Reed: How to be Dead Wrong as a CEO and Still Get Super Rich, Retrieved September 7, 2017 from www.wallstreetonparade.com/2015

McLonglin, Barry. (1996). Risks and Crisis Communication. McLonglin Multimedia Publishing Ltd., Ottawa, Canada.

Nudell, Mayer. (1998). The Handbook for Effective Emergency and Crisis Management. Lexington, Massachussetts, Lexington Books.

O'Brien, Timothy L. (1998). Prince of the Citi: Reed Runs Citicorp with Brains and Pragmatic Skills. Retrieved September 9, 2017 from www.nytimes.com/1998

Sapriel, Caroline. (2003). Effective crisis management: tools, and best practice for the new millennium. Journal of Communication Management, 7(4). https://doi.org/10.1108/13632540310807485

Wigmore, Ivy. (2013). What is Crisis Management? Retrieved September 13, 2017 from www.whatistechterget.com/definition/crisis-management

Wilmarth, Arthur E., Jr. (2014). Citigroup: A Case Study in Managerial and Regulatory Failures. Indiana Law Review, 47, 69-137. 


\title{
The Research on Ecological Chain Structure of High Intelligence Work in the Big Data Era
}

\author{
Yin Fengchun ${ }^{1,2, *} \&$ Yuan Wenli ${ }^{1}$ \\ ${ }^{1}$ Yancheng Teachers University, Yancheng, Jiangsu 224051, China \\ ${ }^{2}$ School of Business, Hohai University, Nanjing, Jiangsu 210098, China \\ *Correspondence: Yancheng Teachers University, Yancheng, China. E-mail: hobbyc@163.com
}

Received: October 9, 2017 Accepted: October 20, 2017 Online Published: October 28, 2017

doi:10.5430/mos.v4n4p29 URL: https://doi.org/10.5430/mos.v4n4p29

\begin{abstract}
In the big data era, highly intelligent job embeddedness promotes organizational ecology, chain value, and development potential. This paper analyzes the nature and representation of intellectual work embedded, and explores the operation mode of big data era intellectual work embedded in the ecological chain, based on cooperative competition ecological chain, value chain, proliferation of ecological symbiotic ecosystem, ecological equilibrium chain, information aggregation structure driven ecological chain, optimizing the environment of the ecological chain.
\end{abstract}

Keywords: big data; high-end talents; job embeddedness; ecological chain; structure

\section{Introduction}

In the era of big data, the degree and level of high intelligence work embeddedness are positively related to the operation level of organizational ecology chain. The higher the degree of embeddedness, the greater the potential motivation, and the higher the value level of the ecological chain embedded in the higher intellectual work. Big data is a collection of data that contains a lot of information, high-speed output, diversified forms, low value density, and real performance. High intelligence refers to those who master systematic theory knowledge or have higher technology and can make important contributions to material civilization, spiritual civilization, political civilization and ecological civilization. Job embeddedness is the analysis of the organizational viscosity of talents from the three dimensions of connection, matching and sacrifice. Work with the ecological chain operation embedding problem to the point of view of high intelligence, in order to show the ecological chain operation form, from the analysis of multiple factors and characteristics, on how to improve the intellectual organization in the ecological chain of job embeddedness, has important significance and practical needs.

\section{The Connotation, Characteristics and Influencing Factors of Embedded Eco Chain in the Era Of Big Data}

\subsection{The Connotation of High Intelligence Work Embedded In Ecological Chain in the Era of Big Data}

In the era of big data, high intelligence work is embedded in the ecological chain. In the era of big data, the process and mode of embedding ecological chain of highly intelligent individuals or groups of work are analyzed from the following three points:

Quantity and quality of eco chain embedded in high intellectual work. The quantity and quality of intellectual work embedded in ecological chain refers to the quantity and quality of high intelligence tissues in the ecological chain. Understand quantity and quality from the angle of human resource. "Quantity" refers to the number of talents who constitute part of the labor force population, and the distribution of "quantity" has a positive correlation with the level of regional economic development; "Quality" is from knowledge, work skills, creative ability, the ability to adapt to the job, organizational management level to examine the input-output ratio of human resources. The higher the ratio, the higher the quality, vice versa. High intelligence belongs to the scarce human resources, and every high intelligence in the organizational ecological chain is of great value. High intelligence quantity and quality is lower than organization demand, the development speed of organization is slow, and finally gets into trouble. The increase 
in the amount of ecological chain can be considered from these aspects: First, the introduction of high intelligence to join the organization, and reasonable matching: to provide high intelligence, attractive jobs, direct recruitment; Create an open and free organizational culture and attract high intelligence. Second, keep the original high aspiration of the organization intact and increase the sacrifice: To give high intelligence, broad career development space, to make full use of intellectual values, can be promoted in the position; The establishment of a smooth, high intelligence assistance mechanism, in a timely manner to find high intellectual difficulties encountered in work life, and help them solve the problem. Third, develop and train excellent members of the organization to become highly intelligent and establish connections: Identify members of the organization and select potential talents for training; The organization regularly provides opportunities for learning and communication within and outside the organization, so that talented people will have the opportunity to enhance their ability to become highly intelligent. Fourth, improve the quality of the ecological chain: Study of professional knowledge, encourage members of on-the-job learning, provide places; work skill, provide independent jobs, so that members can complete a work alone; the cultivation of creative ability, to create an open organization culture, the members of the organization to support multi path to solve the problem; post fit improved distribution post and post selection and combination of independent, so that members have the right to choose jobs; training, organization and management ability of the moderate decentralization, let the organization to participate in the management of high intelligence.

The attributes and behaviors of high intelligence work embedded in ecological chain. Attributes affect behavior, behavior, expression, attributes. An attribute is an abstract concept within. Physically strong, intelligent super, strong psychological quality, wide knowledge, innovative learning ability, usually high intellectual attributes. Behavior refers to the external manifestation of high intellectual attributes. The embedded nature of high intelligence work refers to the integration of highly intelligent individuals into the organizational ecology chain, becoming part of the ecological chain, and mutualism with other parts of the ecological chain. The behavior for the high intelligence into the work of the organization, according to the similarity, intellectual and organizational environment; high intelligence in the working process and organization of large and small, the number of uncertain connection; High intelligence once left the organization will face the sacrifice, the sacrifice may be economic benefits, may also be psychological aspects.

The attributes and behaviors of high intelligence work embedded in ecological chain. Attributes affect behavior, behavior, expression, attributes. An attribute is an abstract concept within. Physically strong, intelligent super, strong psychological quality, wide knowledge, innovative learning ability, usually high intellectual attributes. Behavior refers to the external manifestation of high intellectual attributes. The embedded nature of high intelligence work refers to the integration of highly intelligent individuals into the organizational ecology chain, becoming part of the ecological chain, and mutualism with other parts of the ecological chain. The behavior for the high intelligence into the work of the organization, according to the similarity, intellectual and organizational environment; high intelligence in the working process and organization of large and small, the number of uncertain connection; High intelligence once left the organization will face the sacrifice, the sacrifice may be economic benefits, may also be psychological aspects.

\subsection{Analysis of Embedded Eco Chain in High Intelligence Work in Big Data Era}

In the era of big data, the characteristics of eco - chain construction embedded in high intelligence work are mainly:

The cyclist of high intelligence work embeddedness. The oceans, the land and the space layer each have a circulation system and form a large circulatory system. Example: water evaporates from the ocean into the space layer. Clouds accumulate in the space layer. The rain falls into the land. The rain collects the rivers and flows into the ocean. The process goes round and round. The cycle of high intelligence job embeddedness means that the process of embedding high intelligence work is cyclical and endless. A cycle of experience, trauma, self-repair, growth, and other processes that are embedded in the ecological chain. Establish connection in the early stage of high intelligence, high intelligence into the organization are not very understanding of all aspects of the organization system, culture, personnel, to adapt to various trauma; mid high intellectual adjustment ability through their strong self-repair quickly into the organization; later, high intelligence is fully integrated into the ecological chain, the rapid growth of the ecological chain in the organizational culture and job skills to realize their own ability. In the process of setting up a link, the growth process of high intelligence cycle, makes the degree of job embeddedness more deeply. Organizations are built by people, each with a systematic cycle and a large circulatory system, that is, the ecological chain of organization.

Clustering of highly intelligent job embeddedness. The process of separating sets of different objects into multiple classes consisting of objects of similarity is called clustering. Clustering of highly intelligent job embeddedness 
means that high intelligence also follows classification characteristics when clustering. Like attracts like. Birds of a feather flock together. High intelligence covers a wide range of professional skills, such as: enterprise management personnel, high-tech research and development personnel, professional skills personnel. In the process of job embeddedness, high intelligence is divided into different types of high intelligence because of their respective advantages and skills, and similar types of high intelligence are naturally collected in the ecological chain. In enterprise management, the same type of high intelligence usually comes together in the same department, which is the most common clustering phenomenon. When gathering high intelligence of the same nature, we can complement each other by adding blind areas of cognition, expanding knowledge, colliding ideas, generating innovative thinking and forming a healthy competition. The value of clustering intelligence is much higher than that of a single high intelligence, and in this process, high intelligence itself has realized value added.

Synergy of high intelligence work embeddedness. The synergy of high intelligence work embeddedness refers to the characteristics of coordination and coordination among organizations in order to achieve common goals. In the process of job embeddedness, intellectual and organizational components to establish connections to form a network like structure through a connection with other intellectual part of the flow of information sharing, the internal ecological chain collaboration become possible. A high intellectual synergy state in the work embedded, can give full play to their talents and resources with the help of connectionist networks, by connecting with other network dispatching organization manpower material and financial resources to coordinate, eventually greatly improve the ability to organize the ecological chain complete organizational goals.

Robustness of high intelligence job embeddedness. Robustness is the transliteration of Robust, that is, "robust" and "strong". It is the key to a system that does not crash in cases of unusual and dangerous conditions. The robustness of embedded work with high intelligence refers to the ability of high intelligence to remain stable in the process of job embeddedness without adverse external influences. The improvement of robustness depends on the comprehensive ability improvement of high intelligence itself and the optimization of ecological chain operation mode. High intelligence has a strong sense of competition, in the work, through constant changes, interpersonal relations and environmental adjustment, repeatedly hone professional skills, update knowledge storage, comprehensive promotion of comprehensive ability. The ecological chain in the working path of high MI, select the optimal path between high intelligence and high effective intellectual connection, optimal path through intellectual repeated establishment, operation optimization and overall ecological chain. Enhance robustness in the growth of high intelligence and organizations.

\subsection{Analysis of Influencing Factors of Eco Chain Embedded in High Intelligence Work in the Big Data Age}

The main factors influencing the ecological embeddedness of high intelligence work are:

High intelligence embeddedness, role dynamics, and multiple niche effects. The niche refers to the natural environment, each specific location has different species, special structure, it depends on the relationship between the physiological and behavioral activities and other creatures, so it has its unique niche. High intelligence refers to the dynamic role of the high intelligence in the process of job embeddedness, because of the face of people, things and things continue to change, the high intelligence ideas and working methods are also mature. The reasons for this phenomenon are that the job embeddedness process has multiple niches: First, the ability of high intelligence itself is a complex highly, can handle different types of work; second, high intelligence in the process of job embeddedness, contact and fusion of diverse skills; third, high intelligence and multi role dynamic niche, established the high intelligence and ecological chain and multi direction connection[15]. Promote intellectual job embeddedness. In the process, High intelligence realized the rapid growth of his comprehensive ability, and made the ecological chain run more efficiently and flexibly.

The influence of high intelligence on the changeable information and the ecological field of activity. Information is changeable, which means that information changes at different times and under different circumstances. The field refers to the space, and the activity ecological field refers to the flexible ecological space possessed by high intelligence in the ecological chain of the organization. Information is changing because of changes in environment, time, and flow. The dimension of the information scope increases with the change of interest, and the corresponding processing dimension show a positive proportion. High intelligence in the ecological chain occupies multiple niches, can make high intelligence flexible processing of changeable information, in the dynamic transfer process, formed a flexible ecological field. The establishment of ecological field need to have the following conditions: first, the establishment of an open and inclusive organizational culture, is to determine the key problems existing in the ecological field activities; second, made in support of the ecological niche ecological chain, intellectual ecological field of the activity will be exposed to more nodes in the ecological chain. 
High intelligence embedded in information nodes and cluster ecology can influence. The information node in the ecological chain is the hub of organizing information channels, which has great influence. High intelligence embedded in information nodes has the following advantages: First, high intelligence can enlarge the value, improve ecological efficiency ecological chain; second, High intelligence has deep expertise and strong execution, work to be able to arrange the ecological chain of other individuals, and proposes the reasonable problem case; Third, the professional accomplishment of high intelligence and dedication has a positive impact on other individuals in the ecological chain, and improves the ecological energy of each individual in a number of ways..

\section{Construction of Ecological Chain Embedded in High Intelligence Work in the Big Data Era}

By analyzing the evolution process of the eco chain embedded in the high intelligence work and the structure of the eco chain of high intelligence, the evolution and structure of the embedded eco chain of the high intelligence work in the big data era are studied:

\subsection{Evolution of Embedded Eco Chain in High Intelligence Work in the Big Data Era}

The development of things to follow certain rules, the process of intellectual work embedded has experienced an evolutionary process, which are germination stage(GS), growth period(GP), stable stage(SS), stagflation period(SP), restructuring period $(\mathrm{RP})$ :

\section{Evolution of ecological chain}

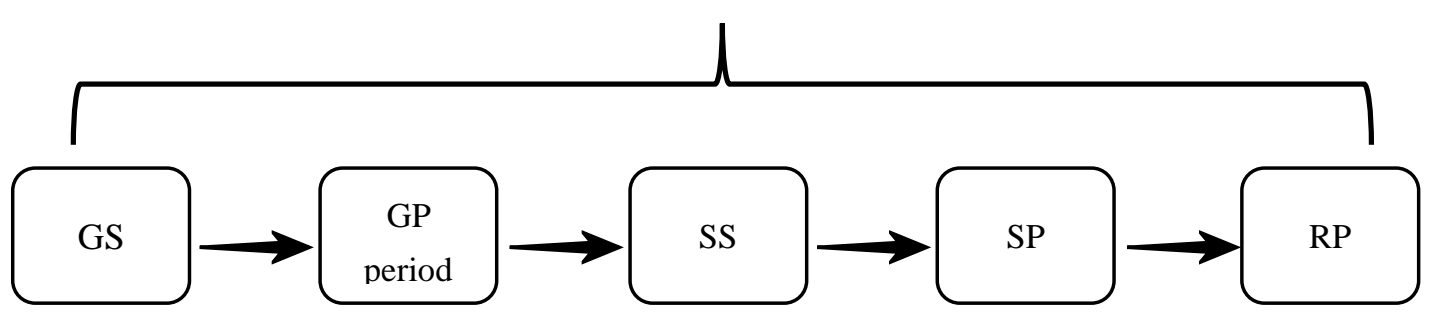

Figure 1. Ecological Chain Evolution

High intellectual work is embedded in the embryonic period of ecology. The embryonic stage of high intelligence work embeddedness is that high intelligence enters the organizational ecological chain at the initial stage. High intelligence must be fully aware of their strengths and weaknesses, and judge and fit the position of the formation of matching. This is a process in which High intelligence understands the integration of the ecological chain. High intelligence should set up the correct communication method for the superiors, peers and subordinates in the ecological chain of the organization; Have a clear understanding of the ecological chain in the organization of rules and regulations or internal to the organization, in common; ecological chain problems, development trend and preliminary planning of their organization in the ecological chain development orientation. The embryonic stage of the eco organization embedded in the highly intelligent work is a very delicate period. It is the process of the formal contact with the ecological chain of the high intelligence organizations, and also the process of organizing deep understanding of the high intellectual. During the germination period, organizations need to provide more help and tolerance for higher intellectual ability, which is conducive to high intellectual work Embeddedness and is rooted in the organizational ecology chain.

High intellectual work is embedded in the ecological growth phase. The growth period of high intellectual work embeddedness is the period of rapid development of intellectual organizations. In adapting to the organizational environment, High intelligence absorbs the essence of culture in the organization and develops rapidly, and feeds the result of growth to the ecological chain. The growth of high intelligence can also promote the growth of other members of the ecological chain of the organization, and promote the formation of a healthy competition atmosphere in the organizational ecological chain. At the same time, High intelligence has accumulated rich experience in the growth period. According to the specific circumstances of the ecological chain of the organization, he uses his own innovative thinking and specialized knowledge to solve the problems existing in the optimization of the ecological chain of the organization. During the period of growth, the ecological field of high intelligence activities provides 
enough space to display their talents and promote the healthy development of the ecological chain of the organization.

High intelligence work is embedded in the ecological stable period. High intelligence work embedded in the ecological stable period means that high intelligence has been fully adapted to integrate into the ecological chain. In the period of stability, high intelligence has been able to play a role in the ecological chain, culture, identity and participate in the organization of the ecological chain and the ecological chain into fully familiar with the operation mode, and other intellectual ecological chain to establish a stable social relationship. During this period, high intelligence's own development in the organization and the promotion speed of the development of the ecological chain of the organization, compared to the growth period down, and entered a stable stage of development.

High intellectual work is embedded in the ecological stagflation period. High-end job embeddedness refers to ecological stagnation, in the development of long time, high intelligence in organization on organizational growth and ecological chain to promote the stagnant period. This may include: first, high intelligence in the early to greatly promote the progress of the ecological chain, ecological chain into the higher stage of development, the current high wisdom cannot play the role of the second pilot drive; high, chi in the ecological chain in the long-term development and ecological chain completely assimilated and lost the culture of thinking brought by the collision sparks, competition in the stable development in the fuzzy sense.

High intellectual work is embedded in the ecological recombination phase. The ecological reorganization stage of "High intelligence" work refers to the long-term stagnation development of high intelligence and organizational ecology chain, which will lead to the decline of high intellectual value and the collapse of organizations, and need to be re matched and restructured. In the process of restructuring, high intelligence will face the sacrifice of leaving the organization. It includes material sacrifice and emotional sacrifice. Leaving the original chain of high Chi will re-enter the matching process, looking for their own organizational ecology chain. The original eco chain is also looking for high intelligence to match the needs of organizational development. Reorganization is a way to let the high wisdom and revitalized the ecological chain organization.

\subsection{The Structure of Eco Chain}

High intelligence, job embeddedness, collaborative competition, ecological chain. The ecological chain of cooperative competition refers to the opposite process of unity and interdependence, mutual dependence, mutual guidance and mutual transformation between the two sides of the ecological chain. Competition leads to coordination and coordination leads to competition. The individual in the ecological chain due to the development trend cannot see the global ecological chain, for selfishness thinking, will find a development direction for spontaneous ontology, other individual cooperation and competition continued in the state and the ecological chain. In the process of embedding eco competition into the eco competitive chain, it is necessary to quickly adapt to the eco chain operation mode of cooperation and competition. Must play high intelligence, have strong competition ability, can occupy a place in zoology chain. High intelligence, by analyzing the situation in which he is, calculates his own strengths and weaknesses, and needs to find the right individuals in the ecological chain. Highly intelligent job embeddedness will increase the intensity of competition in the ecological chain and bring impact and vitality to the ecological chain. Let other members of the ecological chain, in this process, maximize their potential, enhance their ability, thereby bringing the entire ecological chain optimization. Cooperation and competition coexist in a collaborative ecological chain, and high intelligence job embeddedness promotes synergy and promotes competition.

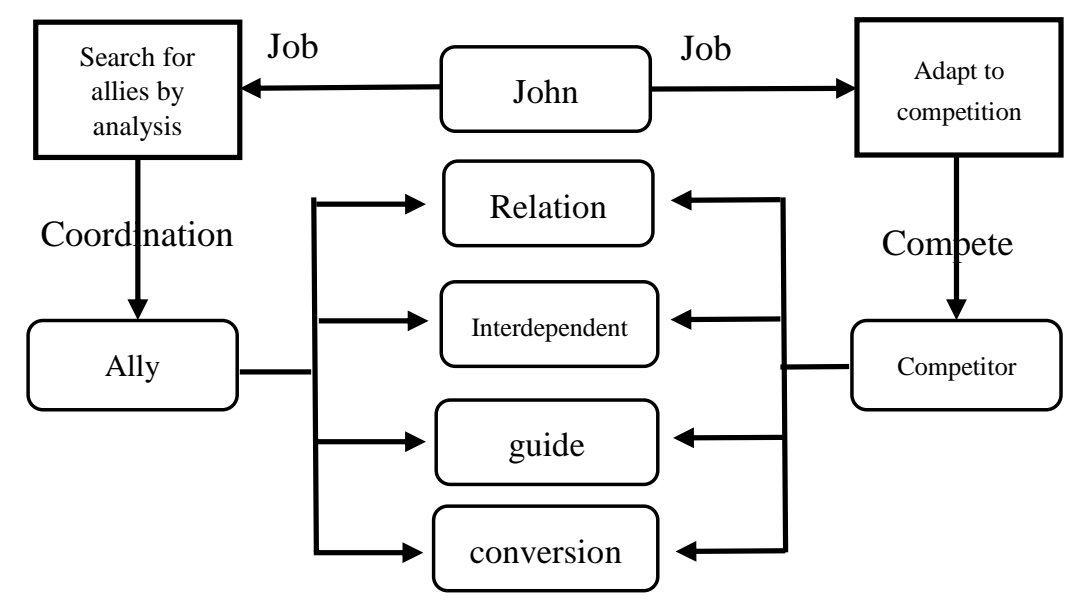


Figure 2. Job Embeddedness Collaborative Competition Eco Chain

High intelligence work, embedded value, proliferation, ecological chain. Value added ecological chain refers to the multiplication of assets through management or operation activities. In this process, although the cost of high intelligence itself is greater than the cost of ordinary human resources, but the value of proliferation in quantity and quality are far more than ordinary human resources. Because has the ability of high intelligence is compound: first, the high complex capability allows high intelligence to play a greater value in the process of embedding, improve work efficiency and achieve the purpose of improving organizational performance; Second, bring this high value proliferation ability of composite will be more comprehensive, not only is the proliferation of organizational ecology chain assets visible, as well as the organization of the ecological chain of intangible assets such as proliferation, proliferation and the ability of the team technical research and development capabilities of value-added and social benefits of the proliferation etc..

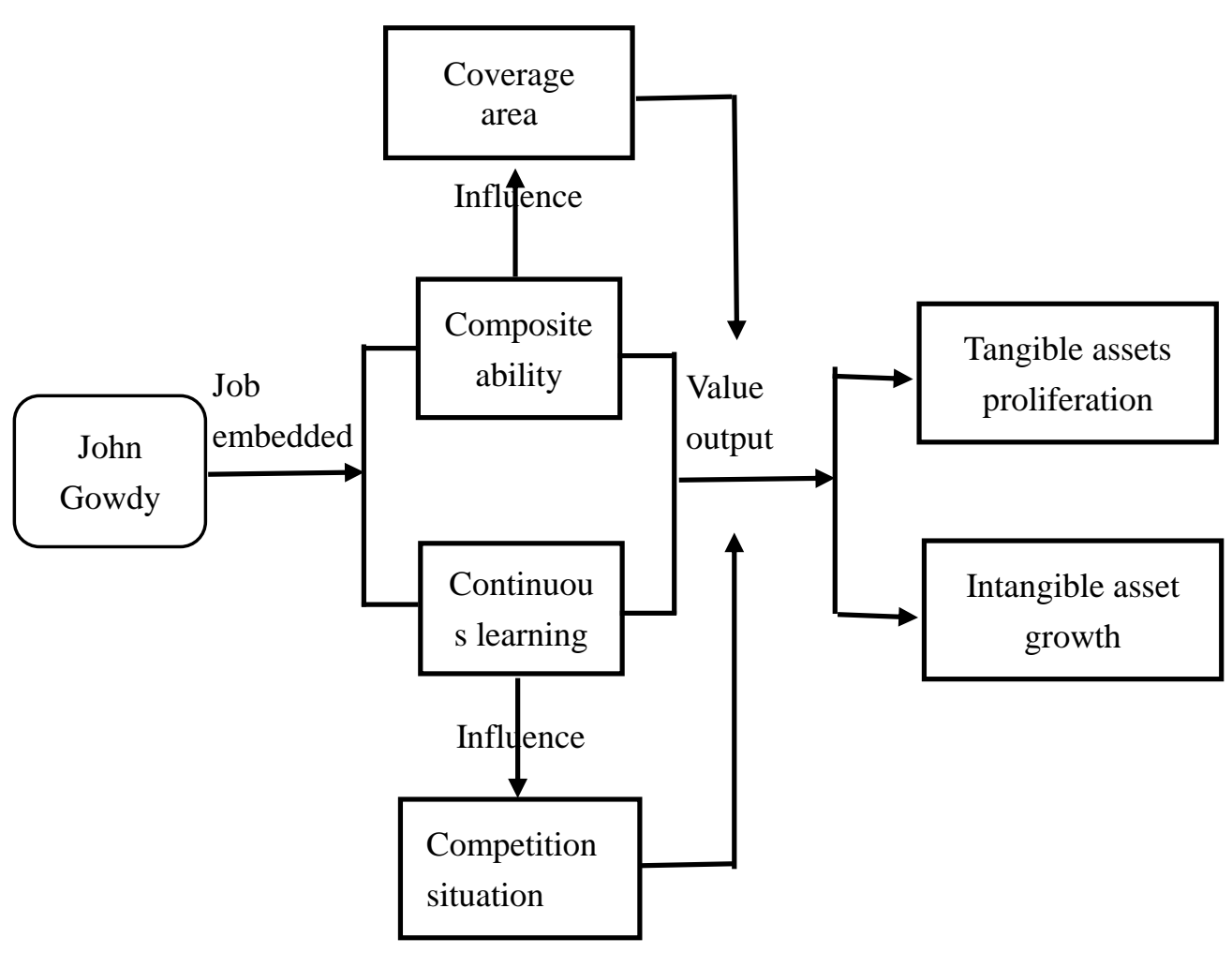

Figure 3. Job Embeddedness, Value Increase, Ecological Chain

High intelligence work, embedded mutualism, ecological chain. Mutualism ecological chain refers to the ecological chain of the various components of cooperation with each other, and this cooperation is beneficial to each other. High intellectual work is embedded in mutually beneficial symbiosis, and ecological chains inevitably coexist with other components of the ecological chain. Under the premise of fierce competition and rapid change of the external environment, each member of the ecological chain has to cooperate with each other to make the ecological chain develop to the maximum extent. High intelligence takes full advantage of its ability and insights into the ability of other members of the ecological chain to identify patterns that maximize symbiosis through identification and analysis. High intelligence job embeddedness will put this symbiotic ecological chain advantage further show the powerful advantage of high intelligence itself will bring more value to other members of the ecological chain symbiosis such as ideas, technology research and development of flexible and efficient operation mode and principle innovation responsible work attitude and so on. 


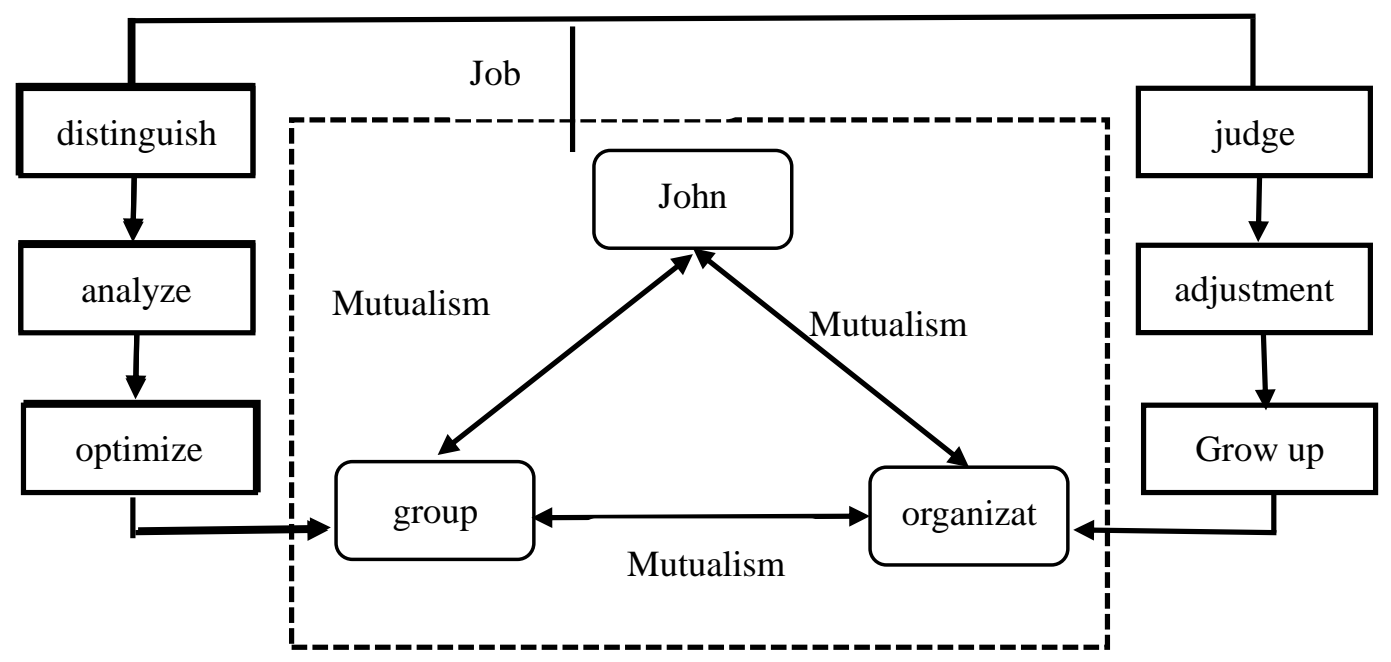

Figure 4. Job Embeddedness Mutualism Ecological Chain

High intelligence, job embeddedness game, equilibrium ecological chain. The game equilibrium ecological chain refers to the existence of the game relationship in each component of the ecological chain. Intellectual work embedded game equilibrium ecological chain will break the initial equilibrium, resulting in a new shock to the entire ecological chain, because in the early work of embedded, high intelligence in the game no matter which party is as strong as foreign aid, to break the situation of well-matched in strength. But in the game equilibrium of the ecological chain, game competition consciousness is very strong, the other side of the game through a variety of ways to enhance one's own competitive ability, the fierce degree of organization in the ecological chain game will be more intense than before, the ecological chain organization will re reach equilibrium situation until high embedded intelligence work after a period of time

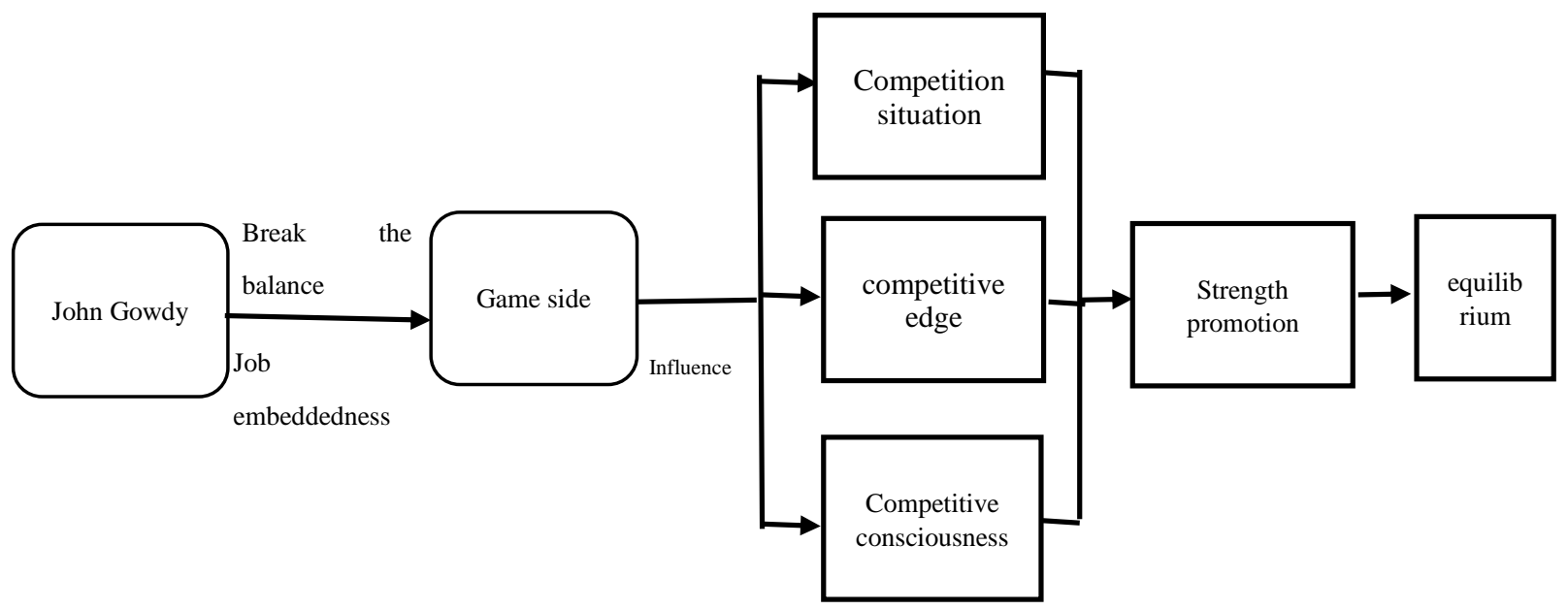

Figure 5. Job Embeddedness, Game Equilibrium, Ecological Chain

High intelligence work, embedded information, cohesion drive ecology. Information aggregation driven ecological chain refers to all kinds of information organization in the ecological chain together, unified cleaning, screening, and summary, and condensed into information ecological chain nodes, the node information as to promote ecological chain operation development impetus. High intelligence is precise in the judgment of information meaning and flexible in dealing with information. High intelligence job embeddedness can improve the driving force from the following aspects: first, the high intelligence itself can directly deal with some emergency information, improve the response speed of ecological chain system; second, system flow high intelligence information 
processing optimization of the original ecosystem, to achieve precise docking data and individual ecological chain; third, high through the establishment of intellectual management system to enhance ecological chain of each individual information and the response speed of execution.

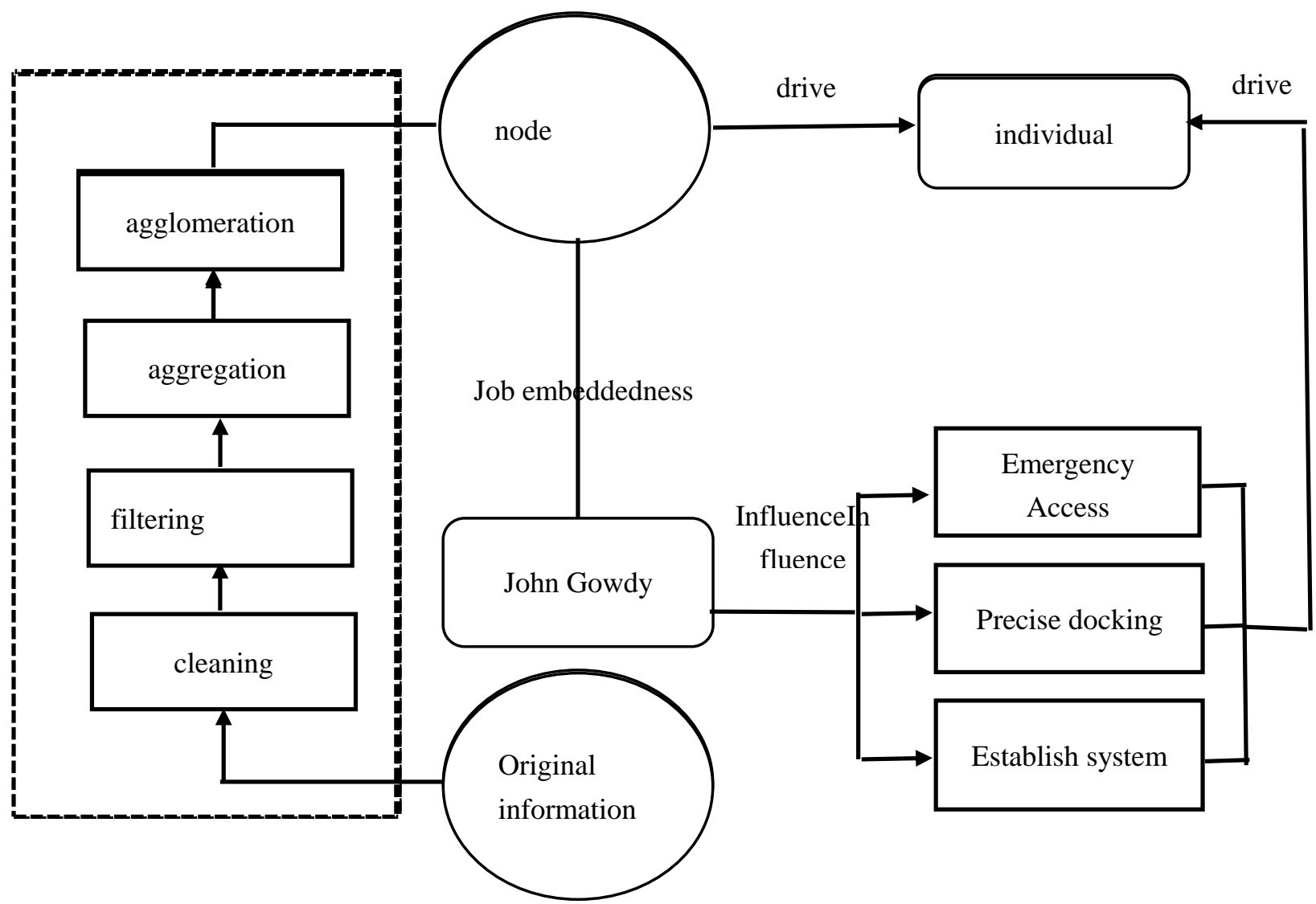

Figure 6. Work Embedding Information to Drive the Eco Chain

High intelligence work, embedded environment, optimization, ecological chain. Environmental optimization ecological chain refers to the ecological chain between high intelligence and ecological chain environment. High intelligence works to embed the environment, optimize the ecological chain, establish links with other individuals in the ecological chain, and form a feedback mechanism with the ecological chain environment. High intelligence directly analyzes the ecological chain environment and optimizes the ecological environment. High intelligence indirectly affects other individuals through their positive energy, which enables other individuals to optimize the ecological chain environment. After the ecological chain environment is optimized, the ecological chain individuals are fed back, and the environment and the individual form a virtuous circle. 


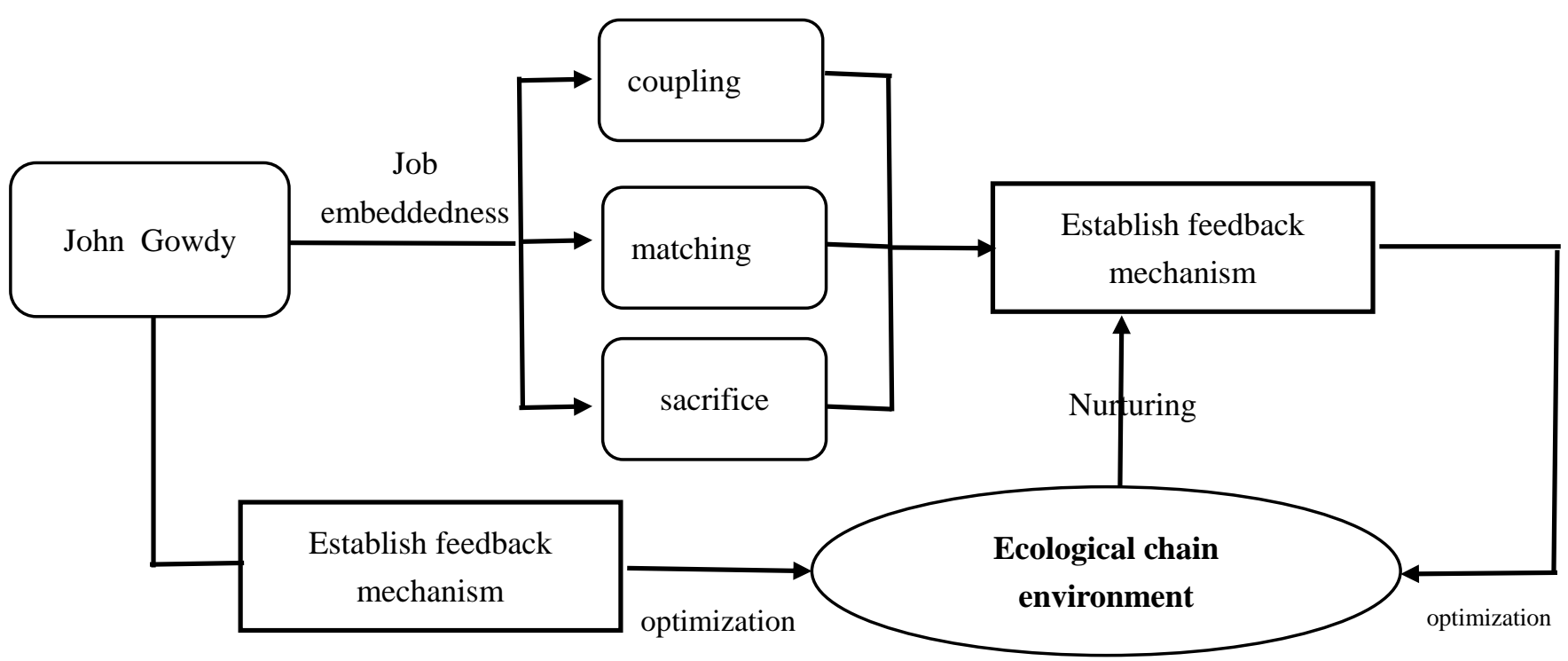

Figure 7. Work Embeddedness, Environment Optimization, Ecological Chain

\section{High Intelligence Work Embedded in the Operation of the Ecological Chain In Big Data Era}

Big data is the main driving force of modern enterprise innovation can create new products or services, improve existing products and services technology level. The use of big data and tools based on big data can greatly promote intelligent work, embedded in the ecological chain of intelligent operation.

\subsection{Simulation Data Guide the Refinement of High Intelligence Work Embedded Collaborative Competition}

The simulated data is static model is knowledge, process knowledge, rules control knowledge, operation logic simulation data is the rule control model of operation model, data processing, data support and drive simulation. Simulation data simulation is used to simulate the possible occurrence of high intelligence in the eco competitive chain of job embededness, and predict the results of collaborative competition in advance, and select the favorable path carefully.

To find out the high degree of organization, the highest wisdom ecological chain collaboration, through the simulation data reflect the result of cooperative competition in the process of guiding direction adjustment, to achieve high intelligence at work embedded in the whole process of fine control, realize the ecological chain to introduce high intellectual value maximization.

\subsection{Cloud Computing to Promote High Intelligence Work, Embedded Value, Proliferation, and Node}

Cloud computing, according to data computing requirements, can be used to idle computer resources on the Internet, similar to networks, servers, storage space, applications, etc., can be attributed to computer resources. Cloud computing is the product of the era of big data burst data, big data era of massive increase the difficulty of the data processing, the development of cloud computing technology to reduce the processing cost of the data by finding the value proliferation organization in the ecological chain of massive data processing, achieve rapid docking process and high value proliferation embedded intelligence work the key of strengthening by intellectual strong management ability, the ecological chain cost every investment can achieve the greatest degree of increase in value through the proliferation point.

\subsection{Intelligent Feedback, Improve High Intelligence Work, Embedded Symbiosis, Networking}

In biology, the more complex the ecological chain, the more species, it shows that the higher the ecological chain, the stronger the robustness, will not easily collapse imbalance. Organization of ecological chain and biological and ecological chain have different approaches but equally satisfactory results, the ecological chain organization from simple to complex development process, to achieve the robustness from weak to strong. System for cleaning, link to collect information on the organization of ecological selection, eventually back to the ecological chain analysis, intelligent feedback, so that the ecological chain can timely adjust and improve the path to ecological chain in the feedback adjustment to network development. In the symbiosis ecological chain, every component of the ecological chain has interdependent relationship, and it can only be win-win if they cooperate with each other in the ecological 
chain, and the stable development of the ecological chain is especially important. Intelligent feedback system provides intuitive and intelligent self-ecological chain optimization process in high intelligence job embeddedness, in every optimization process will assist High intelligence better to promote ecological chain to the direction of network, so that the stability of the ecological chain gradually increased.

\subsection{The Role of Multiple Variables to Promote High Intelligence Work Embedded Game Equilibrium Dynamic}

Role diversification is the demand of modern development, and the high complex ability of high intelligence in the process of job embeddedness makes it possible to diversify the role of high intelligence in the ecological chain. In the game equilibrium ecological chain, the introduction of high intelligence will lead to the competitive advantage of the game side to other game players. However, under the premise of multiple roles, the high intelligence can be added to many games, which results in the fluctuation of the game results in the ecological chain. The ecological chain in the equilibrium conditions, all participants in the game are satisfied with the results, will let the power lost in the ecological chain of the game, the game equilibrium state for a long time will make the ecological chain lost vitality, but the game party occupy absolute advantage will lead to imbalance of ecological chain collapse. High intellectual role diversification, job embeddedness can make the ecological chain in the game equilibrium, dynamic state.

\subsection{Information Cluster Construction, High Intelligence Work, Embedded Information, Aggregation, Matrix}

According to certain similarity, information clustering refers to the classification and collection of information. In the big data age of massive growth of data, the information cluster can preliminarily process the data. The biggest problem encountered in the eco chain of high intelligence work, embedded in the information aggregation drive, is how to handle data efficiently and accurately. The information cluster makes the information no longer simple linear arrangement, but presents the crisscross arrangement way. This arrangement is flexible and flexible, and can be clustered with different information search requirements. The requirement of information is clear and clear, and the difficulty of processing data with high intelligence is reduced.

\subsection{Multiple Drivers to Create High Intelligence Work, Embedded Intelligent Environment, Ecological}

Multiple drivers are more than one driver core. Multiple driving situation: the development of the ecological chain drive more security, development of the ecological chain does not rely solely on a driving force, high intelligence work in multiple embedded ecological chain drive element complement each other, to avoid the phenomenon; three-dimensional driven, development level is more abundant, the formation and development direction of diversification, can to achieve consumption and output coordination in the ecological chain, to achieve organizational ecology. The multiple driving elements complement each other, and the intelligent alternating cycle promotes the ecological development.

\section{Conclusion}

This paper analyzes the essence and represent of the high intelligence work. We discuss its operation mode embedded the ecosystem in big data era through studying coopetition, value hyperplasia, mutualism, Game equilibrium, information aggregation, environment optimization.

\section{Acknowledgement}

This work is supported by National Social Science Foundation of China" Research on high intelligence value identification and job embeddedness feedback tracking model in big data Era" (No. 15BGL101), Six talent peaks project in Jiangsu Province"Research on high intelligence value identification and job embeddedness feedback tracking model in Internet + Era"(No. JY-030), and Young Academic Leaders Funded of Qing Lan Project of Jiangsu Province.

\section{References}

Charlier, Steven D., Guay, Russell P., \& Zimmerman, Ryan D. (2016). Plugged In or Disconnected? A Model of the Effects of Technological Factors on Employee Job Embeddedness. Human Resource Management, 55(1), 109-126. https://doi.org/10.1002/hrm.21716

Chen Yongqiang, Song Ge \& Zhang Wenjing. (2014). Study on the relationship between job embeddedness and turnover intention of expatriate managers in China. Journal of engineering management, 12, 139-144. 
Collins, Brian J., \& Mossholder, Kevin W. (2017). Fairness Means More to Some than Others: Interactional Fairness, Job Embeddedness, and Discretionary Work Behaviors. Journal of Management, 43(2), 293-318. https://doi.org/10.1002/hrm.21716

Cui Xiao Wei \& Wu Xinnian. (2016). Big data applications for large data industry landing. Science and technology management research, 2, 203-207.

Ferreira, Aristides I., Martinez, Luis F., Lamelas, José Pereira, Rodrigues, \& Rosa I. (2015). Mediation of job embeddedness and satisfaction in the relationship between task characteristics and turnover. Vocational Rehabilitation Services, 118-126.

Li Xin \& Li Na. (2015). Research on the development and innovation ability of high-end talents in China. Science and technology management research, 6, 81-84.

Lou CE Qun, Yu Jie \& Nie Ying. (2015). Structural optimization strategy of network information ecological chain. Library and Information Service, 6-11.

Shen Mengling. (2015). The influence mechanism of job embeddedness analysis. China Management Informationization, 18, 94-94.

Wang Quangang \& Zhao Yongle. (2017). Research on factors affecting global high-end talent flow and agglomeration. Science and technology management research, 91-94.

Xu Xiaojun, Wang Yuting \& Zhang Haitao. (2015). Study on the formation mechanism of business information network ecological chain. Journal of Intelligence, 12, 159-164.

Yang Chunjiang \& Li Ran. (2014). Research on the relationship between organizational ethical climate and employee turnover behavior from the perspective of job embeddedness. Chinese Journal of Management, 2014(3), 351-359.

Yang Tingfang. (2015). Organizational embeddedness, community embeddedness, organizational support, perception and turnover intention. Contemporary Finance \& Economics, 2015(6), 351-360.

Yin Fengchun. (2015). Study on embedded value identification of high-end young talents. Science \& Technology Progress and Policy, 24, 138-142.

Yin Fengchun. (2017). Research on introduction, training mechanism and management innovation of top talents. People's Publishing House.

Zhang Haitao, Sun Hongfei, Sun Siyang \& Song Tuo. (2016). Study on optimization model of business network information ecology. Library and Information Service, 3, 110-117.

Zheng Weibo. (2016). Talent turnover and retention from the perspective of matching: a review of research. Human Resources Development of China, 48-55. 


\title{
Impact of Occupational Stress on Job Performance: Moderating Role of Social and Supervisor's Support
}

\author{
Rabia Akhtnar ${ }^{1, *} \&$ Adeel Mustafa ${ }^{2}$ \\ ${ }^{1}$ Riphah International University, Islamabad, Pakistan \\ ${ }^{2}$ Foundation University Islamabad, \\ *Correspondence: Riphah International University, Islamabad, Pakistan. E-mail: rabiaakhter988@gmail.com
}

Received: October 16, $2017 \quad$ Accepted: October 24, $2017 \quad$ Online Published: October 28, 2017

doi:10.5430/mos.v4n4p40 URL: https://doi.org/10.5430/mos.v4n4p40

\begin{abstract}
We use a regression analysis model to inspect a moderating effect of social and supervisor support on occupational stress and job performance. Our sample is based on 251 employees of different organizations. Data congregation approach is based on adoptive survey technique. Our results recommend that there is a strong impact of moderators on occupational stress and job performance.
\end{abstract}

Keywords: regression analysis, social and supervisor support, performance

\section{Introduction}

Occupational stress is considered one of the major problems in any organizational structure as it has a direct impact on the performance of an employee that in turn affects the overall performance of that particular firm/organization. Stress in terms of employee can be in any form like accidents, unsatisfactory job conditions or any kind of illness (Davidson, 1981). Job stress and stress related job issues and then its impact on the performance were the issues raised by Bheer in 1978 .

Recently occupational stress has been renamed as 'Psychosocial Hazard' by some of the researchers and linked to the occupational risk management (McMichael, 1979). This work of McMichael was then further elaborated by Colin D. Butler, to find the major challenges coped with the occupational stress. He considered the physical health issues in relation to the mental stress from job of an employee. Under the condition of the working hours, physical and mental health disorders are being caused by the stress of the work under a particular organization that provides such a stressful environment to the workers (Colin D. Butler, 2015).

On the same stream of line, another research on the physiological health issues in relation to the occupational stress was carried out by James A. Wells et al. where they tried to find out the relation of occupational stress and physical health in association with 12 major measures of the prevailing stress at work and its association with five common health issues. They reached on the analysis that occupational stress has a wide effect on the health of the workers (James A. wells, 2016).

A qualitative analytical approach was used by Jacky Boivin et al. to study and analyze that the stress issues are not only limited to the corporate sector but they are widely spread in each area of work. Those who are providers of health are also suffering with this disease - hospital workers. They had taken the case of the workers who works in the fertility clinic and measure their level of work stress and the impact of that stress on their health. Their results show that fertility clinic staff perceives numerous work-Stressor and sources of difficulties with patients (Jacky Boivin, 2017).

Another remarkable work had been done by Faith Gibson et al. where he reports the analysis of the occupational stress in the social society. In this research they took the large data sample of social worker from Northern Ireland fields. Study formulated a wide part of inter-professional linkage of social workers (Teacher \& Nurses). It was found that the stress in their personal life is much less than the stress they are getting from their jobs (Faith Gibson et al., 2017). 
The question one might can think of, is that the job stress is limited to the occupational employees or the person who are self-employed can also be the target of this problem. To answer this question Jolanda Hessel by using Job Demand Control Model 'JDC' carried out his research. According to this model the increasing demand of the job can increase the stress of the job and if the control factors are employed with the job then this stress can be reduced. After the analysis, they found that self-employed individuals with employees experience more work-related stress than those without employees because of higher job demand (Jolanda et al., 2015).

Due to lack of skills, managerial factors and stumpy social support, workers have to suffer the occupational stress which ten leads to discomfort, exhaustion, psychosocial issues and decline the quality of living which results in increase absenteeism and some of the employees also consider quitting their jobs. (Jani et al., 2014).

Different researches show that physical and mental relaxation play a vital role in the reduction of stress level to $23 \%$. (Jani et al., 2014).

Physical and mental relaxation decreases the stress level moderately. (Jani et al., 2014)

It is also evident from study of Jani and others in 2014 that stress can be reduced by altering work schedule. Organizational need to be more focused on identifying factors that leads toward stress (Jani et al., 2014).

Recovery strategies from stress were identified from 20 firefighters and 7 recovery strategies were found using 2 methods: industrial talks, stress-related discussions, occasion with colleagues and supervisor, workout routine, spare time activities and other leisure experiences (Gargi Sawhney, June 12, 2017).

All recovery strategies, other than stress-related discussion and relaxation, moderated the association between occupational stress and psychological health. Particularly, the affirmative relationship between occupational stress and psychological health was stronger while firefighters found low instead high recovery strategies (Gargi Sawhney, June 12, 2017).

When workforce identifies strong organizational support, their socio-emotional requirements are considered to be fulfilled and they are expected to have additional constructive work attitudes, together with job satisfaction. On the other hand, if employees do not experience supported by the organization they may refuse to give effort (consequentially poor levels of performance) and report more negative job attitudes. A strong positive relationship was exposed by the meta-analysis of Rhoades and Eisenberger (2002) between organizational support, job satisfaction and job performance. We reproduce these outcomes and suggest in our existing model that employees' who observe higher levels of organizational and Supervisor's support will also describe higher levels of job satisfaction and will reveal higher levels of performance. In the following sections we describe the moderating role of supervisor's support and Social support in the relationships occupational stress and job performance.

Social support affects sense of community and life satisfaction (Hyun Jung Oh, 2014). The moderating effects of social support have formed different results. While several studies have establish moderating effects (e.g., Abdul-Halim, 1982), others have not (e.g., Ganster et al., 1986) or have originate support for an opposite moderating effect (e.g., Kaufmann \& Beehr, 1986). An inverse moderating effect is experienced with the relationship of stress and performance.

Prospective moderators of these relations were weak, suggesting the subsistence of four common constructs of stress, job performance, social support and supervisor's support. A range of models for social support and Supervisor's support for occupational stress were examined for this general constructs. Consequences shows that social and supervisor's support had an effect on occupational stress - job performance relations. Social and supervisor's support concentrated the stress faced, mitigated supposed stress, and moderated the occupational stress - job performance association. Moreover, the disagreement that social support is mobilized when stressors are faced was not reliable with the available observed facts. A comparable need of support was set up to influence that support is require when stressors are faced and that support is provided when persons are affected with stress.

\section{Theoretical Background and Research Hypothesis}

\subsection{Occupational Stress}

Job or occupational stress is not only restricted to the men but also poorly striking the women as well. In this contemporary world, we come across many operation associated to the participation of Women in the managerial and supervisory posts which is the most emerging issue in developing countries. In the struggle of getting the administrative position in the organizations, women also have to face the stress issues. Study has been conducted by Gourie Suraj -Narayan, in which he proceeds that at which intensity, women on the administrative posts are getting 
stress. He consider the sample of 30 women on administrative positions with different background and conclude that the stress effects the women on all levels of the managerial positions, the conservation approach to stress handling through multidimensional framework was mainly suitable (Gourie, 2017).

Any situation that makes you feel upset, irritated or uneasy can result in stress. As everyone has different perceptions and thinking processes, their way of coping with issues can heavily vary. That is why, no two people will counter closely in the same mode to a particular state of affair.

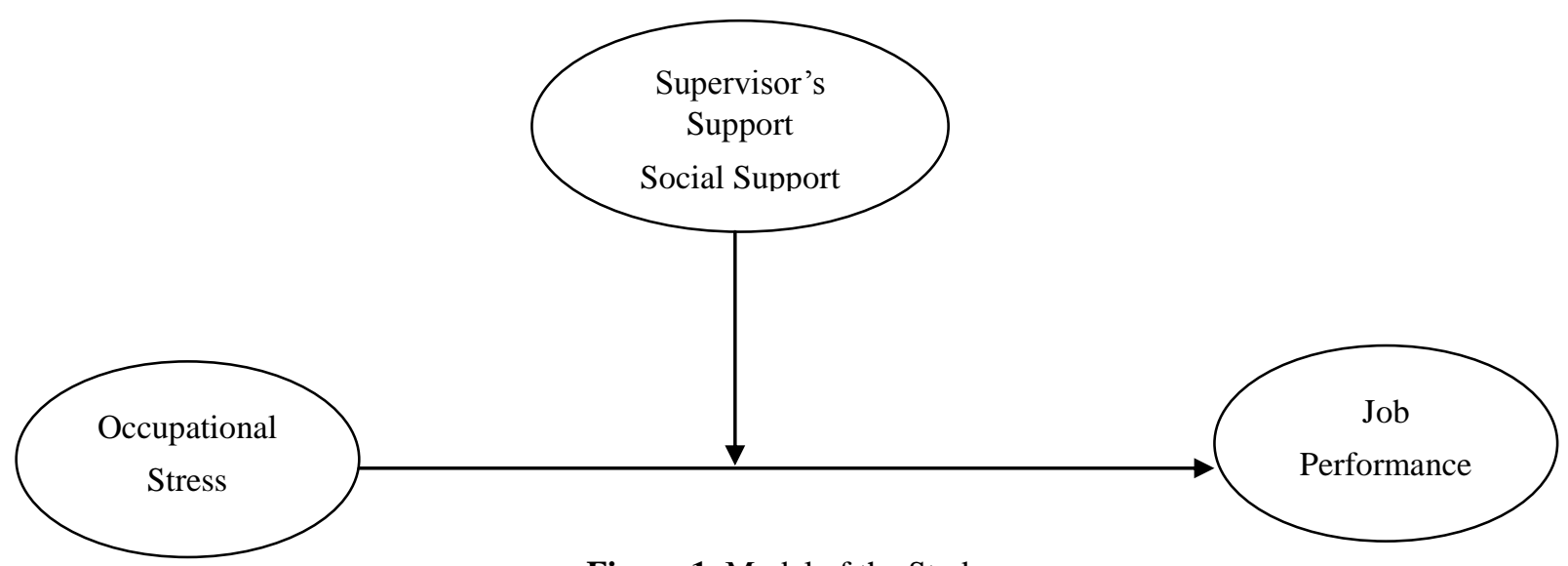

Figure 1. Model of the Study

\subsection{Occupational Stress and Job Performance}

Occupational stress is considered as a great distress to employees of the organizations. Researchers are of the same opinion that stress is a severe issue in many organizations (Cooper and Cartwright, 1994; Varca, 1999; Ornelas and Kleiner 2003). The occupational stress cost heavily for many organizations in current era. For example, the International Labour Organisation (ILO) reports that occupational inefficiencies may cost up to $10 \%$ of a country's GNP (Midgley, 1996).

Occupational stress is also caused by short of resources and equipment; work routine (e.g. overtime) and organizational environment are considered as major contributors to employees stress. Occupational stress results in high frustration among the employees, low job performance, exhaustion and ineffectual interpersonal relations (Manshor, Rodrigue, and Chong, 2003). Johnson (2001) also argued that identifying the signs of stress, the probable effects of such signs and establishing possible projected solutions for such signs are mandatory.

On the basis of such discussions and studies we have develop our hypothesis that the stress faced by the organization have a significant negative impact on the performance of the employees.

\section{H1: Occupational Stress will have a negative significant effect on job performance.}

\subsection{Social Support and Job Performance}

Social support is commonly identified and sound studied. There are a number of ways to define social support. Therefore, it is difficult to recognize just one. Still, the subsequent important basics are frequent in most definitions: social support "may be regarded as resources provided by others, as cooping assistance, as an exchange of resources, or even as a personality trait". Distinct from social integration, which describes the quantitative way to show a person's social relationships; social support also characterizes the qualitative aspects of interaction. Researchers have the same opinion that giving and getting social support is an effective method and should be taken under the perception of reciprocity, refers to give support that is certainly related with getting it.

Social support at all levels is mandatory and cannot be denied. In general, most of the people found socially supported in their lives, moreover, at the workplace. 5th European Working Conditions Survey (EWCS) in 2010 reported 73\% respondent felt supported by the peers and colleagues and $63 \%$ by the managers. Though, it is significant to remind that this information is simply delegate European context. For instance, the First Korean Working Conditions Survey in 2005 showed only $29 \%$ of South Korean being supported by their peers and colleagues.

On the basis of the past studies, we have constructed a hypothesis for our study and suppose that the social support positively effect and impact on job performance. In other words we can say that the person who are supported socially perform well in their professional career. 


\section{H2: Social Support will have a positive significant effect on job performance.}

\subsection{Supervisor's Support and Job Performance}

Supervisors are primary stage of administration where they specified with key responsibilities to shape and direct employees in organizations (Elangovan \& Karakowsky, 1999; Goldstein \& Ford, 2002; Noe 2008). They take part in a vital position as a mediator between administration and operational workers. As an organizer, difficulty handler and role model, supervisors frequently work along with their workers to plan, execute and observe the managerial policies, measures and strategy, as well as instructing programs (Comstock, 1994; Robbins \& DeCenzo, 2004; Ellinger et al., 2005).

The supervisor's responsibility in guidance programs is repeatedly considered as a significant organizational environment element where it can manipulate the efficiency of guidance programs (Noe, 1986, 2008; Blanchard \& Thackers, 2007). Many scholars like Facteau et al. (1995), Chiaburu and Tekleab (2005), and Ismail et al. (2007) analyse that supervisor's position in such instructional areas has two significant qualities: communication and support. Support is mostly associated with supervisor who encourages and provide opportunities for improvement of employees' performance at work place (MacNeil, 2004; Noe, 2005). In a instructional circumstances, supervisors encourage and inspire trainees to participate in such training programs, assist them throughout the programs regarding time, budget assistance and resources. Supervisor may also participate in vital roles for taking effective decisions with the participation of employees, and lead them about the new ways to achieve organizational targets. (Elangovan \& Karakowsky, 1999; Nijman, 2004; Tai, 2006).

In the light of above discussions we consider that supervisor support have a significant positive effect on job performance. The employees who get support from their supervisors perform well in achieving organizational objectives.

\section{H3: Supervisor's support will have a positive significant effect on job performance.}

\subsection{Moderating Role of Social Support between Occupational Stress and Job Performance}

The moderating hypothesis (e.g., Kirmeyer \& Dougherty, 1988; LaRocco, House, \& French, 1980) states that social support interacts with stressors to affect strains; specifically, the relationship between stressor and strain is thought to be stronger for those individuals with low levels of support. To test for moderator effects, the most widely used data-analytic strategy involves examining the increase in R2 when the interaction term (the cross-product of stressors and support) is added to the regression equation of strain on the main effects of stressors and support.

According to the previous discussions and finding we consider social support have a moderating effect on the stress and job performance relationship. Considering that the employees who are socially supported can cope up with the stress more easily and effectively perform their organizational obligations.

\section{H4: Social support will moderate the relationship between occupational stress and job performance in a way that} this negative relationship will be weaker.

\subsection{Moderating Role of Supervisor's Support between Occupational Stress and Job Performance}

Supervisor's role is measured as suggesting and assessing organizational customs for effective dealing with workers that demonstrate how manager gives importance to the employees in effectively performing their duties. The organizational support theory explains that if an employee receives high level support from the organization, his output will improve (Eisenberger et al., 2001). It has already been accepted with a number of studies that organizational support is related with the job performance; make supportive surroundings among peers, establishing and contributing new ideas for the improvement of organization, and completion of organizational responsibility (Eisenberger et al., 1990; Shore \& Wayne, 1993). From above debate it can be accomplished that more supervisor's support leads towards added devoted approach toward performance of the organizational duties, in contrast to the employees do not supported by the organization.

Under the organizational support theory, we consider supervisor's support as a moderator of our study, having an effect that such support can reduce the stress of the organization and work and will help the employees in improving their performance.

H5: Supervisor's support will moderate the relationship between occupational stress and job performance in a way that this negative relationship will be weaker. 


\section{Research Methodology}

\subsection{Sample and Data Collection Procedures}

Data for this study was collected from employees of different service sector private organizations. The sector was considered to be useful for the study because they have to be more alert and vigilant regarding the completion of their tasks, are unsecure regarding their jobs, stressed by more efficiently producing the effective results. Convenience sampling technique was used to collect data. Self-administered survey questionnaire method was used for the collection of data. A cover letter was attached with the questionnaire which explains the purpose of the study to the respondent. Confidentiality and unanimity was ensured to the respondents. The participation was voluntary.

A total of 300 questionnaires were distributed. 268 questionnaires were returned out of which 17 were un-useable due to incomplete or multiple answers of the same question. Overall response rate was $83.6 \%$ on the basis of total useable questionnaires. $65.1 \%$ of the respondents were male and the remaining $33.3 \%$ were females. Average age of the respondents was between 25-54 years. Major of the respondents were between the ages of 25-34 years accumulating 53.3\% respondent. The respondents include a number of married, Single, divorced and widow. $49 \%$ respondents were married. Most of them have children along with them. The respondents have the education of Bachelor's, Master's, Professional or Doctorate degrees. $72.5 \%$ respondents hold a master's degree.

\subsection{Measures and Scales Used}

All study variables were measured at different scale. Occupational Stress, Job Performance and Supervisor's Support were measured at a scale of 1-5. Social Support was measured at 1-7 measure scale.

\subsection{Occupational Stress}

This variable was measured using a 16 item scales of Caplan, R.D., Cobb, S., French, J.R.P., Jr., Harrison, R.V. and Pinneau, S.R. (1975) "Job Demands and Worker Health, HEW Publication No. (NIOSH), pp. 75-160". The scale ranges from 1-5 describing the work situation and environment of the respondents. One sample item of the scale is "There is a difference of opinion among the members of my department". The cronbach's alpha reliability of the scale was 0.665 considered to be a reliable measure.

\subsection{Job Performance}

Job performance was measured using a 17 item scales of Cammann, C., Fichman, M., Jenkins, D., \& Klesh, J. (1979) "The Michigan Organizational Assessment Questionnaire Unpublished manuscript, University of Michigan, Ann Arbor". The scale ranges from 1-5, describes how often have the respondent done each of the item on your present job. Scale of $1=$ Never, $2=$ Once or twice, $3=$ Once or twice per month, $4=$ Once or twice per week and $5=$ every day. One sample item of the scale is "Stayed home from work and said you were sick when you weren't". The cronbach's alpha reliability of the scale was 0.938 .

\subsection{Social Support}

Social support was measured by a 25 item scale of Weinert, C. (1987) "A social support measure: PRQ85. Nursing Research, 36, 273-277". Scale ranges from 1-7 describing about the respondents personal opinions regarding their social relations. Scale of $1=$ Strongly Disagree, $2=$ Disagree, $3=$ Somewhat Disagree, $4=$ Neutral, $5=$ Somewhat Agree, $6=$ Agree and $7=$ Strongly Agree. One sample item of the scale is "I spend time with others who have the same interests that I do". The cronbach's alpha reliability of the scale was 0.810 .

\subsection{Supervisor's Support}

Supervisor's support was measured through a 7 item scale of McCreary, D. R., and Thompson M. M. (2006). Development of two reliable and valid measures of stressors in policing: The operational and organizational police stress questionnaires. International Journal of Stress Management, 13(4), 494-518. Scale ranges from 1-5 indicating the support of supervisor within the organization of respondent. Scale of $1=$ Strongly Disagree leads towards $5=$ Strongly Agree. One sample item of the scale is "My supervisor gives me credit for things I do well". The cronbach's alpha reliability of the scale was 0.742 . 


\subsection{Control Variables}

Table 1. ONE-WAY ANOVA

\begin{tabular}{lrr}
\hline & $\mathrm{F}$ & $\mathrm{p}$ \\
\hline Gender & 7.480 & .007 \\
Age & 13.557 & .000 \\
Marital Status & 18.991 & .000 \\
No. of Children & 4.773 & .003 \\
Education & 2.225 & .067 \\
\hline
\end{tabular}

We use gender, age, marital status and no. of children as control variables due their probable significant direct effect on DV (Job Performance). A one-way ANOVA comparing job performance and occupational stress across gender, age, marital status, no. of children and education revealed that there were significant differences in occupational stress and job performance across organizations due to such demographic factors as gender $(\mathrm{F}=7.480, \mathrm{p}<.05)$, age $(\mathrm{F}=13.557, \mathrm{p}<.05)$, marital status $(\mathrm{F}=18.991, \mathrm{p}<.05)$ and no. of children $(\mathrm{F}=4.773, \mathrm{p}<.05)$. Education is not considered as a control variable due to its insignificant effect on such relationship.

\section{Results}

\subsection{Descriptive, Reliability, Correlation and Regression Analysis}

Table 2 present descriptive statistics, bivariate correlations, and reliability (coefficient) for all actions. Zero-order bivariate correlations were in the expected direction.

Table 2. Descriptive, Reliability and Correlation Analysis

\begin{tabular}{|c|c|c|c|c|c|c|c|}
\hline & & Mean & SD & OS & SUS & SOS & $\mathbf{J P}$ \\
\hline$\overline{\text { OS }}$ & & & & $(.665)$ & & & \\
\hline & Pearson Correlation & 3.234 & .389 & 1 & & & \\
\hline SUS & & & & & $(.742)$ & & \\
\hline SOS & Pearson Correlation & 3.420 & .613 & .038 & 1 & $(.810)$ & \\
\hline JP & Pearson Correlation & 5.027 & .681 & .048 & $.265 * *$ & 1 & (.938) \\
\hline & Pearson Correlation & 1.738 & .810 & -.004 & -.118 & $-.141 *$ & 1 \\
\hline
\end{tabular}

** Correlation is significant at the 0.01 level (2-tailed)

* Correlation is significant at the 0.05 level (2-tailed)

Values in () shows the cronbech alpha reliability of the scale.

\subsection{Regression Analysis}

We apply multiple linear regression analysis to examine all main effect hypotheses (Hypothesis 1,2 and 3 ). We entered gender, age, marital status and no. of children in the first step as control variables, followed by all independent and moderating variables. Table 2 (Step 2) shows the results for the main effects of OS and JP on the outcomes. JP was negatively related to $\operatorname{OS}(\beta=0.090, p<.001)$ and positively related to Supervisor's support $(\beta$ $=.010, p<.001)$ and Social Support $(\beta=.303, p<.05)$. These results supported Hypothesis 1,2 and 3 .

\subsection{Moderating Influence of Supervisor's and Social Support}

We apply moderated multiple regression analysis (Cohen, Cohen, West, \& Aiken, 2003) to test Hypothesis 4 and 5. We entered the control variables at first step, then the independent and moderator variables in next step. We entered the interaction terms of the independent and moderator variables at the third step, which will confirm the moderation if significant.

Results available in Table 3 (Step 3) show that, controlling for the effects of OS, SuS and SoS, the interaction term 
of OS $\times$ SuS was significant for Job Performance $(\beta=0.202, p<.05 ; \Delta R 2=.02, p<.05)$ and interaction term of OS $\times$ SoS was also significant $(\beta=0.363, p<.001 ; \Delta R 2=.02, p<.001)$.

We construct the important interactions terms to check the high and low values moderation on the graph. The graph of such significant interactions terms are shown in Figures 1 and 2. Figure 1 shows that, the relationship of Occupational Stress and Job Performance weakens in the presence of Supervisor's Support.

Table 3. Regression Analysis

\begin{tabular}{lccc}
\hline & \multicolumn{1}{c}{ JP } & \\
\hline Step 1 & B & R Square & Change in R Square \\
Control Variables & & & \\
Gender & & .161 & \\
Age & & & \\
Marital Status & & & .049 \\
No. of children & & & \\
Step 2 & & & \\
OS & -.090 & .211 & \\
SuS & .010 & & \\
SoS & .303 & & \\
Step 3 & & & \\
OSxSuS & .202 & & \\
OCxSoS & .363 & & \\
\hline
\end{tabular}

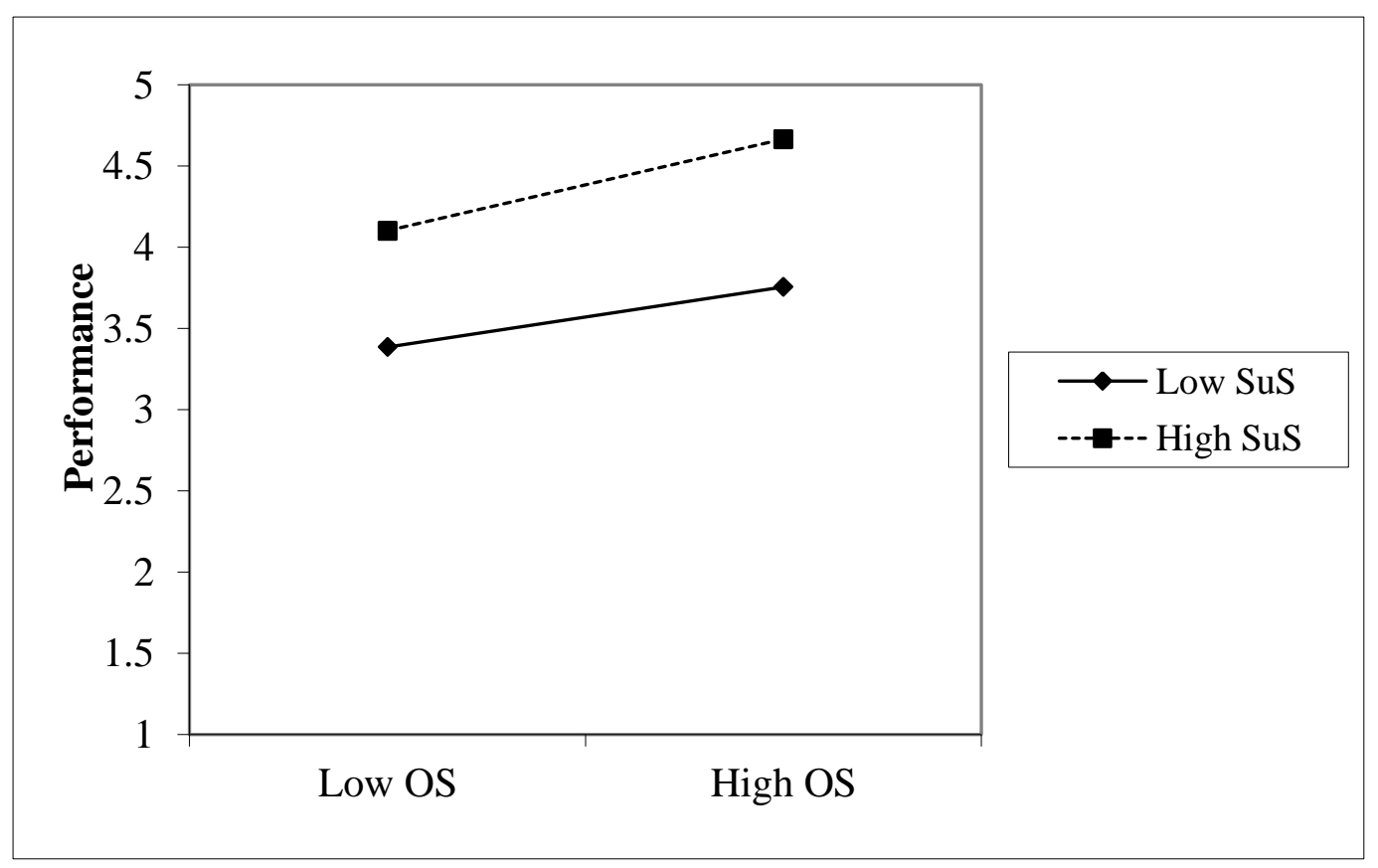

Figure 1. Effect of Supervisor's Support on Job Performance 
Figure shows the plot of the significant interaction for job performance. The slope for low and high Occupational Stress is significantly affected by the moderator and the slope is more steeper which means that in the existence of Supervisor's Support the employees can better perform their job duties and assignments and can better cope with the stress. The results supported Hypothesis 4 for Occupational Stress and Job performance being affected by the Supervisor's Support.

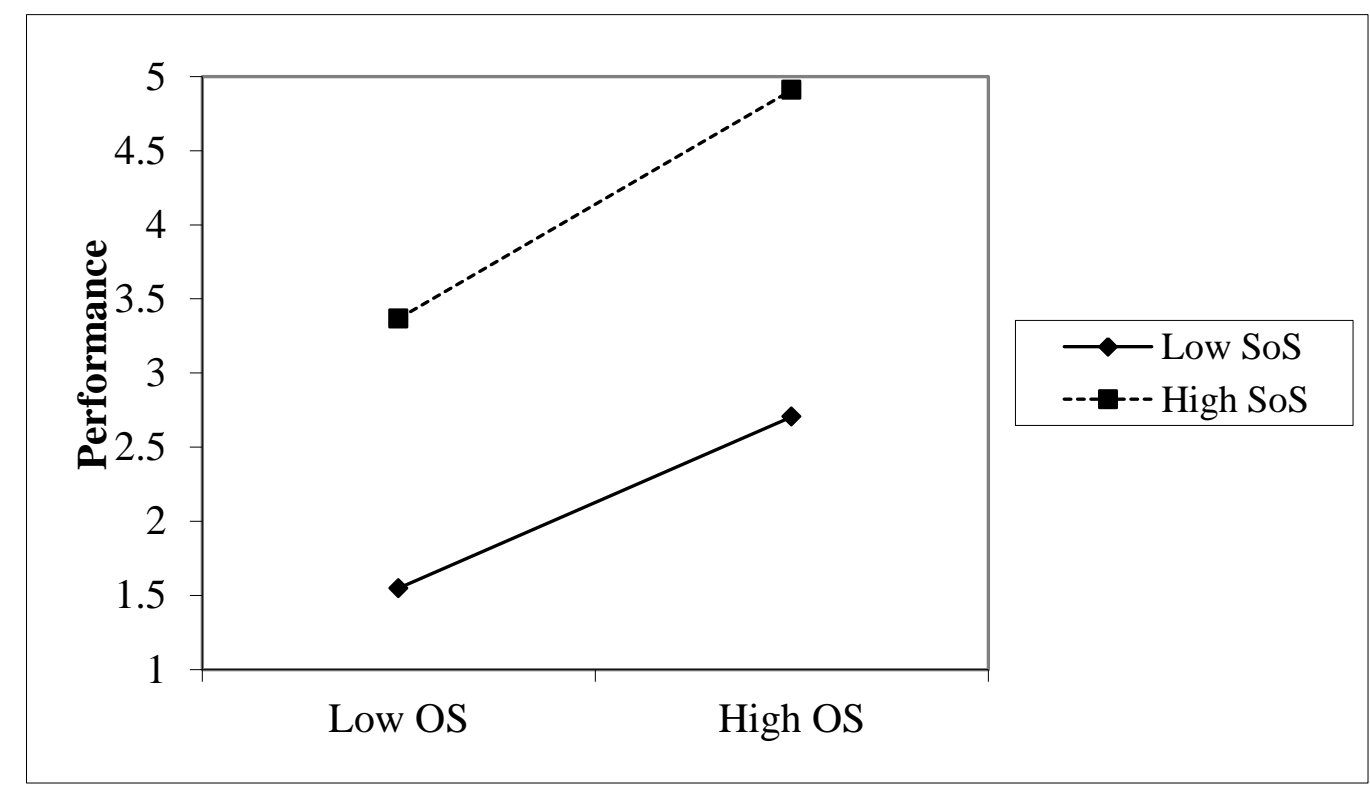

Figure 2. Effect of Social Support on Job Performance

Figure 2 shows the plot of slope for Occupational stress and job performance which is moderated by Social Support. The results supported Hypothesis 5 for Occupational Stress and Job Performance being affected by Social Support.

\section{Conclusions and Implications}

\subsection{Practical Implications}

The study can be useful for the managers to cope up with the employees facing stress. Supervisors can relate certain factors to effect job performance. They can also find the reasons of poor performance by the employees, whether such performance is due to the organizational factors or due to their personal life issues. Managers, associates and personal relations of the employees can play a better role for improved productivity and performance of the employees and can make them enable to perform better in the society and for the organization.

\subsection{Limitations and Direction for Future Study}

Due to less time and resources the study has certain limitations. Due to time constraints convenient sampling technique was used for collection of data. Sample size was comparatively small and collected from a small sector. Cross sectional design was used which create a common method bias.

Future researchers can use probability sampling technique for more accurate findings and results. They can also increase the sample size so that the results can be generalized over a larger population; and can also study these variables with reference to a specific industry. The relationship of Occupational stress and job performance can also be moderated or mediated with other variables like coping style of the individual, personality, background, culture etc.

\subsection{Discussion}

Empirical evidences shows that most of our hypotheses, which were proposed for study, are supported. Occupational stress is found to be negatively affecting job performance of an employee which is the acceptance of our H1 which was related to the negative and significant effect of occupational stress on job performance.

Social support is found to be positively affecting job performance that is the reason for accepting our $\mathrm{H} 2$ which 
shows the employees supported socially can positively perform their job's functions and duties.

Supervisors support is positively and significantly found to effect job performance that support our $\mathrm{H} 3$ that employees can perform better if they are supported by their supervisors.

The moderated regression and graphs presents that the two factors i.e. Social Support and Supervisors Support are being affecting the relationship of Occupational Stress and Job Performance in a positive way. The person who is being supported socially and supervisory can better perform for the organization. So, our H4 and H5 also find empirical evidences to be supported.

\section{References}

Beehr, T. A. (1978). Job stress, employee health and organizational effectiveness: A facet analysis, model, and literature review. Personnel Psychology, 31(4), 655-699. https://doi.org/10.1111/j.1744-6570.1978.tb02118.x

Beehr, T. A. (1994). Psychological stress in the workplace. New York: Rout ledger.

Beehr, T. A. (1985). The role of social support in coping with organizational stress. Human stress and cognition in organizations, 375-398.

Davidson, M. J. (1981). A model of occupational stress. Journal of Occupational Medicine, X4-574.

Day, D. V. (1991). Predicting Job Performance Across Organizations: The Interaction of Work Orientation and Psychological Climate. Journal of Management, 17(3), 589-600. https://doi.org/10.1177/014920639101700304

Eisenberger, R. A. (2001). Reciprocation of perceived organizational support. Journal of Applied Psychology, 86(1), 42-51. https://doi.org/10.1037/0021-9010.86.1.42

Gargi Sawhney, K. S. (June 12, 2017). Occupational Stress and Mental Health Symptoms: Examining the Moderating Effect of Work Recovery Strategies in Firefighters. Journal of Occupational Health Psychology.

Hyun Jung Oh, E. O. (2014). How does online social networking enhance life satisfaction? The relationship among online supportive interaction, affect, perceived social support, sense of community, and lofe satisfaction. Computers in Human Behavior, 69-78.

Jackson, S. E. (1985). A meta-analysis and conceptual critique of research on role ambiguity and role conflict in work settings. Organizational Behavior and Human Decision Processes, 36(1), 16-78. https://doi.org/10.1016/0749-5978(85)90020-2

Jacky Boivin, L. B. (2017). Perceived challenges of working in a fertility clinic: a quantitative analysis of work stressors and difficulties working with patients. Human Reproduction, 32(2), 403-408. https://doi.org/10.1093/humrep/dew326

Jani H Ruotsalainen, J. H. (12,2014). Preventing Occupational Stress in Healthcare Workers. Cochrane Occupational Safety and Health Group.

Jiaxi Peng, D. L. (2014). How can core self-evaluations influence job burnout? Th ekey roles of organizational commitment and job satisfaction. Journal of Health Psychology.

John H., \& Crump, C. L. (1980). Investigting Occupational Stress: A Methodological Approach. Journal of Occupational Behaviour, 19-204.

Jolanda Hessels, C. A. (n.d.). Self-employment and work related stress: The mediating role of job control and job demend. Journal of Business Venturing, 19 pages.

Kinicki, A. J. (1996). Occupational health. Journal of Vocational Behavior, 49(2), 190-220. https://doi.org/10.1006/jvbe.1996.0040

LaRocco, J. M. (1980). Social support, occupational stress and health. Journal of Health and Social Behavior, 21(3), 202-218. https://doi.org/10.2307/2136616

Leavy, R. L. (1983). Social support and psychological disorder: A review. Journal of Community Psychology, 11(1), 3-21. https://doi.org/10.1002/1520-6629(198301)11:1\%3C3::AID-JCOP2290110102\%3E3.0.CO;2-E

Suraj-Narayan, G. (2005). Women in Management and Occupational Stress. Empowering Women for GenderEquity, 83-94.

Xiaoxi Wang, L. L. (2017). Associations of Occupational Stressors, Perceived Organizational Support and 
Phychological Capital with Work Engagement among Chinese Nurses. BioMed Research International, 11 pages.

\section{RIPHAH INTERNATIONAL UNIVERSITY}

\section{Faculty of Management Sciences}

\section{Work Opinion Survey}

Dear Sir/Madam,

I, Rabia Akhtar, student of MS Riphah International University, Islamabad. To fulfill the course requirement, I have to conduct a research on the moderating effects of Social and Supervisor's Support on Relationship of Occupational Stress and job performance.

I would like to know about your work environment and how it affects you. This information is not available anywhere else. Your answers on the enclosed forms are needed.

PLEASE DO NOT PUT YOUR NAME ON ANY OF THE FORMS PROVIDED. Your answers are to remain anonymous. The information, which you provide will be combined with other answers only in statistical summaries.

Thank you for your cooperation and support.

Regards,

MS Scholar

Rabiaakhter988@gmail.com 


\section{Section A}

\section{Occupational stress}

Caplan, R.D., Cobb, S., French, J.R.P., Jr., Harrison, R.V. and Pinneau, S.R. (1975). Job Demands and Worker Health. HEW Publication No. (NIOSH), pp. 75-160.

NIOSH Generic Job Stress Questionnaire. (n.d.): The National Institute for Occupational Safety and Health

Scoring Key For NIOSH Generic Job Stress Questionnaire. (n.d.). The National Institute for Occupational Safety and Health

Please answer the following questions about your work situation

\begin{tabular}{|c|c|c|c|c|c|}
\hline & $\begin{array}{l}\text { Strongly } \\
\text { Disagree }\end{array}$ & Disagree & Neutral & Agree & $\begin{array}{c}\text { Strongly } \\
\text { Agree }\end{array}$ \\
\hline \multicolumn{6}{|l|}{ There is harmony in my department } \\
\hline \multicolumn{6}{|l|}{$\begin{array}{l}\text { In our department, we have lots of bickering over } \\
\text { who should do what job }\end{array}$} \\
\hline \multicolumn{6}{|l|}{$\begin{array}{l}\text { There is difference of opinion among the members } \\
\text { of my department }\end{array}$} \\
\hline \multicolumn{6}{|l|}{ There is dissension in my department } \\
\hline \multicolumn{6}{|l|}{$\begin{array}{l}\text { The members of my department are supportive of } \\
\text { each other's ideas }\end{array}$} \\
\hline \multicolumn{6}{|l|}{$\begin{array}{l}\text { There are clashes between subgroups within my } \\
\text { department }\end{array}$} \\
\hline \multicolumn{6}{|l|}{$\begin{array}{l}\text { There is friendliness among the members of my } \\
\text { department }\end{array}$} \\
\hline \multicolumn{6}{|l|}{$\begin{array}{l}\text { There is "we" feeling among members of my } \\
\text { department }\end{array}$} \\
\hline \multicolumn{6}{|l|}{$\begin{array}{l}\text { There are disputes between my department and } \\
\text { other departments }\end{array}$} \\
\hline \multicolumn{6}{|l|}{$\begin{array}{l}\text { There is agreement between my department and } \\
\text { other department }\end{array}$} \\
\hline \multicolumn{6}{|l|}{$\begin{array}{l}\text { Other departments withhold information for the } \\
\text { attainment of our department tasks }\end{array}$} \\
\hline \multicolumn{6}{|l|}{$\begin{array}{l}\text { The relationship between my department and } \\
\text { other departments is harmonious in attaining the } \\
\text { overall organizational goals }\end{array}$} \\
\hline \multicolumn{6}{|l|}{$\begin{array}{l}\text { There is lack of mutual assistance between my } \\
\text { department and other departments }\end{array}$} \\
\hline \multicolumn{6}{|l|}{$\begin{array}{l}\text { There is cooperation between my departments } \\
\text { and other departments }\end{array}$} \\
\hline \multicolumn{6}{|l|}{$\begin{array}{l}\text { There are personality clashes between my } \\
\text { departments and other departments }\end{array}$} \\
\hline $\begin{array}{l}\text { Other departments create problems for my group } \\
\text { Your job }\end{array}$ & & & & & \\
\hline
\end{tabular}




\section{Section B}

\section{Supervisor Support}

McCreary, D. R., and Thompson, M. M. (2006). Development of two reliable and valid measures of stressors in policing: The operational and organizational police stress questionnaires. International Journal of Stress Management, 13(4), 494-518.

Please use the following response scale to indicate the extent to which you agree with each statement regarding supervisor support in your organization. Please choose the scale that is most closely applicable for each statement.

\begin{tabular}{|l|l|l|l|l|l|}
\hline & $\begin{array}{c}\text { Strongly } \\
\text { Disagree }\end{array}$ & Disagree & Neutral & Agree & $\begin{array}{c}\text { Strongly } \\
\text { Agree }\end{array}$ \\
\hline $\begin{array}{l}\text { My supervisor is concerned about the welfare of } \\
\text { those under him or her. }\end{array}$ & & & & & \\
\hline My supervisor pays attention to what I am saying. & & & & & \\
\hline My supervisor is helpful in getting the job done. & & & & & \\
\hline $\begin{array}{l}\text { My supervisor is successful in getting people to } \\
\text { work together. }\end{array}$ & & & & & \\
\hline My supervisor gives me credit for things I do well. & & & & & \\
\hline My supervisor criticizes me for small things. & & & & & \\
\hline My supervisor backs me up if there is a problem. & & & & & \\
\hline
\end{tabular}

\section{Section C}

\section{Social Support}

Weinert, C. (1987). A social support measure: PRQ85. Nursing Research, 36, 273-277.

Below are some statements with which some people agree and others disagree. Please read each statement and CIRCLE the response most appropriate for you. There is no right or wrong answer.

$$
\begin{aligned}
& 1=\text { STRONGLY DISAGREE } \\
& 2=\text { DISAGREE } \\
& 3=\text { SOMEWHAT DISAGREE } \\
& 4=\text { NEUTRAL } \\
& 5=\text { SOMEWHAT AGREE } \\
& 6=\text { AGREE } \\
& 7=\text { STRONGLY AGREE }
\end{aligned}
$$

\section{STATEMENTS}


1. There is someone I feel close to who makes me feel secure.

\begin{tabular}{|l|l|l|l|l|l|l|}
\hline 1 & 2 & 3 & 4 & 5 & 6 & 7 \\
\hline
\end{tabular}

2. I belong to a group in which I feel important.

\begin{tabular}{|l|l|l|l|l|l|l|}
\hline 1 & 2 & 3 & 4 & 5 & 6 & 7 \\
\hline
\end{tabular}

3. People let me know that I do well at my work (job, homemaking)

\begin{tabular}{|l|l|l|l|l|l|l|}
\hline 1 & 2 & 3 & 4 & 5 & 6 & 7 \\
\hline
\end{tabular}

4. I can't count on my relatives and friends to help me with problems.

\begin{tabular}{|l|l|l|l|l|l|l|}
\hline 1 & 2 & 3 & 4 & 5 & 6 & 7 \\
\hline
\end{tabular}

5. I have enough contact with the person who makes me feel special.

\begin{tabular}{|l|l|l|l|l|l|l|}
\hline 1 & 2 & 3 & 4 & 5 & 6 & 7 \\
\hline
\end{tabular}

6. I spend time with others who have the same interests that I do.

\begin{tabular}{|l|l|l|l|l|l|l|}
\hline 1 & 2 & 3 & 4 & 5 & 6 & 7 \\
\hline
\end{tabular}

7. There is little opportunity in my life to be giving and caring to another person.

\begin{tabular}{|l|l|l|l|l|l|l|}
\hline 1 & 2 & 3 & 4 & 5 & 6 & 7 \\
\hline
\end{tabular}

8. Others let me know that they enjoy working with me (jobs, committees, projects).

\begin{tabular}{|l|l|l|l|l|l|l|}
\hline 1 & 2 & 3 & 4 & 5 & 6 & 7 \\
\hline
\end{tabular}

9. There are people who are available if I needed help over an extended period of time.

\begin{tabular}{|l|l|l|l|l|l|l|}
\hline 1 & 2 & 3 & 4 & 5 & 6 & 7 \\
\hline
\end{tabular}

10. There is no one to talk to about how I am feeling.

\begin{tabular}{|l|l|l|l|l|l|l|}
\hline 1 & 2 & 3 & 4 & 5 & 6 & 7 \\
\hline
\end{tabular}


11. Among my group of friends we do favors for each other.

\begin{tabular}{|l|l|l|l|l|l|l|}
\hline 1 & 2 & 3 & 4 & 5 & 6 & 7 \\
\hline
\end{tabular}

12. I have the opportunity to encourage others to develop their interests and skills.

\begin{tabular}{|l|l|l|l|l|l|l|}
\hline 1 & 2 & 3 & 4 & 5 & 6 & 7 \\
\hline
\end{tabular}

13. My family lets me know that I am important for keeping the family running.

\begin{tabular}{|l|l|l|l|l|l|l|}
\hline 1 & 2 & 3 & 4 & 5 & 6 & 7 \\
\hline
\end{tabular}

14. I have relatives or friends that will help me out even if I can't pay them back.

\begin{tabular}{|l|l|l|l|l|l|l|}
\hline 1 & 2 & 3 & 4 & 5 & 6 & 7 \\
\hline
\end{tabular}

15. When I am upset there is someone I can be with who lets me be myself.

\begin{tabular}{|l|l|l|l|l|l|l|}
\hline 1 & 2 & 3 & 4 & 5 & 6 & 7 \\
\hline
\end{tabular}

16. I feel no one has the same problems as I.

\begin{tabular}{|l|l|l|l|l|l|l|}
\hline 1 & 2 & 3 & 4 & 5 & 6 & 7 \\
\hline
\end{tabular}

17. I enjoy doing little “extra” things that make another person's life more pleasant.

\begin{tabular}{|l|l|l|l|l|l|l|}
\hline 1 & 2 & 3 & 4 & 5 & 6 & 7 \\
\hline
\end{tabular}

18. I know that others appreciate me as a person.

\begin{tabular}{|l|l|l|l|l|l|l|}
\hline 1 & 2 & 3 & 4 & 5 & 6 & 7 \\
\hline
\end{tabular}

19. There is someone who loves and cares about me.

\begin{tabular}{|l|l|l|l|l|l|l|}
\hline 1 & 2 & 3 & 4 & 5 & 6 & 7 \\
\hline
\end{tabular}

20. I have people to share social events and fun activities with.

\begin{tabular}{|l|l|l|l|l|l|l|}
\hline 1 & 2 & 3 & 4 & 5 & 6 & 7 \\
\hline
\end{tabular}


21. I am responsible for helping provide for another person's needs.

\begin{tabular}{|l|l|l|l|l|l|l|}
\hline 1 & 2 & 3 & 4 & 5 & 6 & 7 \\
\hline
\end{tabular}

22. If I need advice there is someone who would assist me to work out a plan for dealing with a situation.

\begin{tabular}{|l|l|l|l|l|l|l|}
\hline 1 & 2 & 3 & 4 & 5 & 6 & 7 \\
\hline
\end{tabular}

23. I have a sense of being needed by another person.

\begin{tabular}{|l|l|l|l|l|l|l|}
\hline 1 & 2 & 3 & 4 & 5 & 6 & 7 \\
\hline
\end{tabular}

24. People think that I'm not as good a friend as I should be.

\begin{tabular}{|l|l|l|l|l|l|l|}
\hline 1 & 2 & 3 & 4 & 5 & 6 & 7 \\
\hline
\end{tabular}

25. If I got sick, there is someone to give me advice about caring for myself.

\begin{tabular}{|l|l|l|l|l|l|l|}
\hline 1 & 2 & 3 & 4 & 5 & 6 & 7 \\
\hline
\end{tabular}

\section{Section D}

\section{Job Performance}

Cammann, C., Fichman, M., Jenkins, D., \& Klesh, J. (1979). The Michigan Organizational Assessment Questionnaire. Unpublished manuscript, University of Michigan, Ann Arbor

How often have you done each of the following things on your present job?

\begin{tabular}{|c|c|c|c|c|}
\hline 1 & 2 & 3 & 4 & 5 \\
\hline Never & Once or Twice & $\begin{array}{c}\text { Once or Twice per } \\
\text { month }\end{array}$ & $\begin{array}{c}\text { Once or Twice per } \\
\text { week }\end{array}$ & Every Day \\
\hline
\end{tabular}

1. Daydreamed rather than did your work.

\begin{tabular}{|l|l|l|l|l|}
\hline 1 & 2 & 3 & 4 & 5 \\
\hline
\end{tabular}

2. Stayed home from work and said you were sick when you weren't.

\begin{tabular}{|l|l|l|l|l|}
\hline 1 & 2 & 3 & 4 & 5 \\
\hline
\end{tabular}


3. Taken a longer break than you were allowed to take.

\begin{tabular}{|l|l|l|l|l|}
\hline 1 & 2 & 3 & 4 & 5 \\
\hline
\end{tabular}

4. Started or continued a damaging or harmful rumor at work.

\begin{tabular}{|l|l|l|l|l|}
\hline 1 & 2 & 3 & 4 & 5 \\
\hline
\end{tabular}

5. Been nasty or rude to a others.

\begin{tabular}{|l|l|l|l|l|}
\hline 1 & 2 & 3 & 4 & 5 \\
\hline
\end{tabular}

6. Insulted someone about their job performance.

\begin{tabular}{|l|l|l|l|l|}
\hline 1 & 2 & 3 & 4 & 5 \\
\hline
\end{tabular}

7. Made fun of someone's personal life.

\begin{tabular}{|l|l|l|l|l|}
\hline 1 & 2 & 3 & 4 & 5 \\
\hline
\end{tabular}

8. Ignored someone at work.

\begin{tabular}{|l|l|l|l|l|}
\hline 1 & 2 & 3 & 4 & 5 \\
\hline
\end{tabular}

9. Started an argument with someone at work.

\begin{tabular}{|l|l|l|l|l|}
\hline 1 & 2 & 3 & 4 & 5 \\
\hline
\end{tabular}

10. Verbally abused someone at work.

\begin{tabular}{|l|l|l|l|l|}
\hline 1 & 2 & 3 & 4 & 5 \\
\hline
\end{tabular}

11. Threatened someone at work with violence.

\begin{tabular}{|l|l|l|l|l|}
\hline 1 & 2 & 3 & 4 & 5 \\
\hline
\end{tabular}

12. Threatened someone at work, but not physically.

\begin{tabular}{|l|l|l|l|l|}
\hline 1 & 2 & 3 & 4 & 5 \\
\hline
\end{tabular}


13. Said something obscene to someone at work to make them feel bad.

\begin{tabular}{|l|l|l|l|l|}
\hline 1 & 2 & 3 & 4 & 5 \\
\hline
\end{tabular}

14. Did something to make someone at work look bad.

\begin{tabular}{|l|l|l|l|l|}
\hline 1 & 2 & 3 & 4 & 5 \\
\hline
\end{tabular}

15. Played a mean prank to embarrass someone at work.

\begin{tabular}{|l|l|l|l|l|}
\hline 1 & 2 & 3 & 4 & 5 \\
\hline
\end{tabular}

16. Hit or pushed someone at work.

\begin{tabular}{|l|l|l|l|l|}
\hline 1 & 2 & 3 & 4 & 5 \\
\hline
\end{tabular}

17. Insulted or made fun of someone at work.

\begin{tabular}{|l|l|l|l|l|}
\hline 1 & 2 & 3 & 4 & 5 \\
\hline
\end{tabular}

\section{Section E}

\section{Background Information}

Please provide the following information about yourself.

1. What is your gender?
a. Male
b. Female

2. How old are you?
a. $<18$
b. $18-24$
c. $25-34$
d. $35-44$
e. $45-54$
f. $55-64$
g. $\quad 65-74$
h. $>74$ 
3. What is your marital status?
a. Married
b. In a relationship
c. Single, never married
d. Single, divorced
e. Single, widowed

4. If you have children living at home, how many are in each of the following age groups?
a. Less than 4 years old
b. 4 through 12 years old
c. 13 through 18 years old
d. 19 and older

5. What is the highest completed level of education?
a. Secondary school
b. High school
c. College
d. Bachelor's degree
e. Master's degree
f. Professional degree
g. Doctorate degree 